\title{
Action Potential-Independent and Nicotinic Receptor- Mediated Concerted Release of Multiple Quanta at Hippocampal CA3-Mossy Fiber Synapses
}

\author{
Geeta Sharma, Michael Grybko, and Sukumar Vijayaraghavan \\ Department of Physiology and Biophysics and Neuroscience Program, University of Colorado at Denver and Health Sciences Center, Aurora, Colorado \\ 80045
}

Presynaptic action potential-independent transmitter release is a potential means of information transfer across synapses. We show that in the hippocampal mossy fiber boutons, activation of the $\alpha 7$-subtype of nicotinic acetylcholine receptors ( $\alpha 7$-nAChRs) results in a large increase in the amplitude of spontaneous events, resulting from concerted release of multiple quanta from the mossy fiber boutons. This amplitude increase is abolished at low temperatures. Activation of $\alpha 7$-nAChRs causes a rise in intraterminal calcium at mossy fiber boutons, involving ryanodine receptors. Regulation of concerted release requires the subsequent activation of presynaptic calcium/ calmodulin-dependent protein kinase II (CaMKII). Activation of CaMKII is required to drive presynaptic action potential-independent transmission at the mossy fiber-CA3 pyramidal cell synapse. The effects of $\alpha 7$-nAChR activation are mediated by biologically relevant doses of nicotine. Our results demonstrate a novel form of synaptic plasticity mediated by presynaptic $\alpha 7$-nAChRs and store calcium that is temporally different and might respond to a different history of synaptic activity than that mediated by incoming action potentials.

Key words: nicotine; addiction; synaptic plasticity; synaptic vesicle release; acetylcholine receptor; synaptic communication; multivesicular; mEPSCs

\section{Introduction}

Most studies on synaptic plasticity describe events triggered by incoming presynaptic action potentials (APs). The random nature of spontaneously occurring miniature excitatory and inhibitory currents (mEPSCs and mIPSCs) has resulted in the assumption that these events might be inconsequential. However, studies demonstrating that neurotransmitters alter postsynaptic excitability (Sharma and Vijayaraghavan, 2003; Shigetomi and Kato, 2004) and potentially shape neuronal development (Murphy et al., 1994; Saitoe et al., 2001; Sutton et al., 2004) have justified a re-examination of the role of mEPSCs in modulating synaptic strength.

Previous studies suggest that small, subthreshold depolarizations can travel large distances down axons, and can serve as analog modulators of AP-driven transmitter release (Alle and Geiger, 2006). In addition, local modulation of release at synaptic terminals can result in postsynaptic firing both in small (Shigetomi and Kato, 2004) as well as complex (Sharma and Vijayaraghavan, 2003) terminals.

Several interesting features of spontaneous transmitter release

\footnotetext{
Received Aug. 29, 2007; revised Jan. 14, 2008; accepted Jan. 16, 2008

This work was supported by National Institute of Drug Abuse Grant R01 DA 10266 and Cutting-Edge Basic Research Awards Grant 5 R21 DA019453 to S.V. and by the American Heart Association Scientist Development Grant to G.S.

Correspondence should be addressed to Sukumar Vijayaraghavan, Department of Physiology and Biophysics, University of Colorado at Denver and Health Sciences Center, Mail Stop 8307, P.0. Box 6511, 12800 East 19th Avenue, Aurora, C0 80045. E-mail: sukumar.v@uchsc.edu.

D0I:10.1523/JNEUROSC1.5407-07.2008

Copyright $\odot 2008$ Society for Neuroscience $\quad$ 0270-6474/08/282563-13\$15.00/0
}

have been reported. mEPSC and mIPSC amplitudes are modulated by store calcium (Llano et al., 2000; Sharma and Vijayaraghavan, 2003; Collin et al., 2005; Gordon and Bains, 2005). These studies suggest that calcium sources, other than voltagegated calcium channels (VGCCs), might have an important role in regulating synaptic strength.

Activation of nicotinic acetylcholine receptors (nAChRs) containing the $\alpha 7$ subunit ( $\alpha 7$-nAChRs) causes calcium-induced calcium release from endoplasmic reticulum (ER) stores, leading to increased release of glutamate from hippocampal mossy fiber boutons (MFBs). This modulation involves the generation of large-amplitude mEPSCs, and is sufficient to drive the postsynaptic neuron above threshold (Sharma and Vijayaraghavan, 2003). Thus, mEPSC-mediated modulation, might represent a form of plasticity distinct from AP-driven mechanisms in the CNS (Sharma and Vijayaraghavan, 2003).

One way of increasing synaptic strength and the fidelity of transmission is by the release of multiple quanta closely spaced in time. Multivesicular release (MVR; the synchronized release of multiple quanta from a single active zone) and concerted univesicular release across active zones are potential means of altering synaptic strength. MVR has been demonstrated in a number of systems (Tong and Jahr, 1994; Wall and Usowicz, 1998; Wadiche and Jahr, 2001; Christie and Jahr, 2006; Foster et al., 2005), suggesting that many synapses might employ this process to alter synaptic strength.

Mechanisms underlying concerted release of multiple quanta, however, remain unknown. In their simplest forms, MVR can be 
thought of as resulting from increased probability of release $\left(P_{\mathrm{R}}\right)$. The findings that MVR occurs at both high- $P_{\mathrm{R}}$ and low- $P_{\mathrm{R}}$ sites (Auger et al., 1998; Wadiche and Jahr, 2001; Oertner et al., 2002; Christie and Jahr, 2006), as well as the existence of only univesicular release at other CNS synapses (Silver et al., 2003), raise the possibility that concerted release of multiple quanta might require the activation of specific signaling pathways.

A number of questions remain unanswered regarding the mechanisms and biological relevance of nAChR-mediated concerted release of multiple quanta. In this study we show that the large-amplitude mEPSCs arise from presynaptic summation of smaller release events caused by increases in intracellular calcium concentration $\left([\mathrm{Ca}]_{\mathrm{i}}\right)$ after activation of $\alpha 7$-nAChRs on MFBs. This synchrony arises downstream of ER calcium release and requires the activation of calcium/calmodulin-dependent protein kinase II (CaMKII). Concerted release of glutamate can be mediated by biologically relevant doses of nicotine at these synapses suggesting that the mechanism might play a significant role in synaptic plasticity during drug addiction.

Our data indicate a presynaptic AP-independent form of short-term plasticity at the mossy fiber synapses driven by nAChRs.

\section{Materials and Methods}

Transverse hippocampal slices (300 $\mu \mathrm{m}$ thick) were prepared from 12 - to 16-d-old Sprague Dawley rats using a Leica (Nussloch, Germany) VT1000S Vibratome, or DTK-zero 1 (Dosaka, Kyoto, Japan), in accordance with institutional guidelines (Sharma and Vijayaraghavan, 2003). Slices were then incubated in a bicarbonate based medium [artificial CSF (ACSF)] containing (in mM) $120 \mathrm{NaCl}, 3.5 \mathrm{KCl}, 26 \mathrm{NaHCO}_{3}, 1.25$ $\mathrm{NaH}_{2} \mathrm{PO}_{4}, 10$ glucose, $2.5 \mathrm{MgCl}_{2}$, and $1 \mathrm{CaCl}_{2}$, for at least an hour before the experiment.

Electrophysiological recordings. Recording conditions were the same as described previously (Sharma and Vijayaraghavan, 2003). Briefly, all recordings were performed at room-temperature $\left(21-23^{\circ} \mathrm{C}\right)$, except where noted, using a Zeiss (Oberkochen, Germany)Axioskop FS microscope. Slices were continuously perfused with bubbled ACSF containing $2.5 \mathrm{~mm}$ $\mathrm{CaCl}_{2}, 1 \mathrm{~mm} \mathrm{MgCl}, 1 \mu \mathrm{M}$ tetrodotoxin (TTX), and $50 \mu \mathrm{M}$ picrotoxin or $10 \mu \mathrm{M}$ gabazine. Signals were recorded with an Axopatch 200B patch amplifier (Molecular Devices, Sunnyvale, CA) using pClamp 9. Wholecell voltage-clamp and current-clamp recordings were performed on pyramidal cells in the $\mathrm{CA} 3$ region of the hippocampus, using patch pipettes with a resistance of 3-6 M $\Omega$. Internal solution, pH 7.2 (290 mOsm), contained (in mM) $130 \mathrm{~K}$-gluconate, $5 \mathrm{KCl}, 10$ EGTA (or 10 BAPTA), 10 HEPES, 2 ATP (magnesium salt), and 0.2 GTP (sodium salt). Data were filtered at $2 \mathrm{kHz}$ and collected every $100 \mu \mathrm{s}$ for a stretch of $2 \mathrm{~min}$ at a time. Access resistance was monitored at the beginning and end of each $2 \mathrm{~min}$ period. Data were discarded if it varied $>20 \%$ over the course of the experiment. Holding potential was $-60 \mathrm{mV}$. Current-clamp experiments were done in $I=0$ mode using an Axopatch 200B amplifier (Molecular Devices). For these experiments, neither TTX nor GABAR blockers were included in the ACSF.

Data analyses. Events were detected using MiniAnalysis 6.0 software (Synaptosoft, Decatur, GA). The average baseline noise $\left(I_{\mathrm{RMS}}\right)$ was $1.94 \pm 0.07 \mathrm{pA}(n=6$ cells $)$. Events were detected and accepted for analyses using criteria based on threshold amplitude, area under the curve, and time to peak (Sharma and Vijayaraghavan, 2003). A detected mEPSC had to meet all three criteria to be taken for analyses. When the rise of an event occurred during the falling phase of a previous event (as during a burst), the baseline was estimated by the software by extrapolating the decay of the first peak using a first order exponential function. Each event was visually examined to protect against software errors. Further analysis was done using Origin software (Microcal, Northampton, MA).

All amplitudes were binned at $4 \mathrm{pA}$ and frequency at $1 \mathrm{~s}$ or as described in the text. Average data are presented as mean \pm SEM. Kinetics of the AMPA and kainate (KA) components were determined from 10-30 dig- itally averaged traces. All rise times were calculated over 10-90\% of peak and expressed as such. The decay times listed in this study are decay time constants $(\tau)$, obtained from a single exponential fit using the Origin software. Charge transfer was calculated by measuring the area under the averaged traces.

All distributions were compared for statistical significance using the nonparametric Kolmogorov-Smirnov test. Means were compared using paired or unpaired Student's $t$ test. All significance values provided are two-tailed $p$ values.

Calcium imaging. Slices were loaded with Fura 2-AM using one of two protocols. The first protocol was modified from a previously published protocol (Regehr and Atluri, 1995). Briefly, a $1 \mathrm{~mm}$ solution of Fura 2 -AM was made in DMSO containing $20 \%$ pluronic acid. This was then diluted 100-fold in ACSF. The dye was filled in a patch pipette. The pipette was lowered till it touched the stratum lucidum, perpendicular to the orientation of mossy fibers. The dye was then pressure injected for $30-45 \mathrm{~min}$. The slices were allowed to recover for $1-2 \mathrm{~h}$ during which time the dye diffused down the axons. Imaging sites were selected 100$200 \mu \mathrm{m}$ away from the injection site. In the second protocol, slices were incubated in $20 \mu \mathrm{M}$ Fura 2 -AM in $0.2 \%$ pluronic acid for an hour at RT and allowed to recover a further hour. Both protocols gave adequate labeling of MFBs. In a few experiments, the tip of a patch pipette was smeared with Dye I paste (NeuroTrace; Invitrogen, Carlsbad, CA) and placed at the granule cell layer. The slices were then incubated for $1-2 \mathrm{~h}$ at $35^{\circ} \mathrm{C}$, followed by Fura 2-AM loading at room temperature. Terminals that were double labeled were positively identified as MFBs.

Imaging was performed using a Zeiss Axioskop-2 upright microscope using a water-immersion $40 \times$ lens (numerical aperture, 0.8 ). Images were acquired using a cooled CCD camera (Cooke Sensicam; PCO, Kelheim, Germany). Excitation was achieved using a Sutter Instruments (Novato, CA) DG-4 fast wavelength switcher and standard Fura 2 excitation and emission filters were used (Chroma Technology, Brattleboro, VT). Images were acquired and processed using the SlideBook software (Intelligent Imaging Innovations, Denver, CO). Ratiometric data were acquired at $0.1-1 \mathrm{~Hz}$. Analyzed data were graphed using the Microcal Origin software. Calcium signals were expressed as changes in the $340 /$ 380 ratio.

Agonist was applied using pressure application via a patch pipette placed $\sim 20 \mu \mathrm{m}$ above the slice. Unless otherwise stated, agonist was applied for $30 \mathrm{~s}$.

Materials. $N$-[2-[[[3-(4-chlorophenyl)-2-propenyl]methylamino]methyl]phenyl]-N-(2-hydroxyethyl)-4-methoxybenzenesulfonamide (KN-93) and 2-[N-(4'-methoxybenzenesulfonyl) ] amino- $N$-(4' -chlorophenyl)-2propenyl- $N$-methylbenzylamine phosphate $(\mathrm{KN}-92)$, and TTX were from EMD Biosciences (San Diego, CA). All other chemicals were obtained from either Sigma (St. Louis, MO) or Tocris Bioscience (Ellisville, MO). Dye I and Fura-2 AM were from Invitrogen.

\section{Results}

We have shown previously (Sharma and Vijayaraghavan, 2003) that application of $20 \mu \mathrm{M}$ nicotine causes a burst of highfrequency mEPSCs recorded from CA3 pyramidal cells from 11to 16-d-old rat hippocampal slices. In addition, there is a significant rightward shift in mEPSC amplitude distribution as shown in Figure $1 A$. The amplitude increase is coincident with the onset of the mEPSC frequency change (Fig. $1 B$ ).

\section{nAChR activation results in a long-lasting change in mEPSC amplitudes}

A key feature of the $\mathrm{nAChR}$ effects on mossy fiber mEPSCs is that the amplitude increases outlast the increase in frequency (Fig. $1 C, D)$. In the cell shown in Figure $1 C$, whereas the frequency of the mEPSCs, after application of $20 \mu \mathrm{M}$ nicotine, returned close to baseline frequencies, the cumulative probability distribution of amplitudes remains significantly shifted to the right even 2-4 min after cessation of agonist application $(p<0.0001$, compared with control) (Fig. 1C). This effect is mimicked by $100 \mu \mathrm{M}$ ACh in 

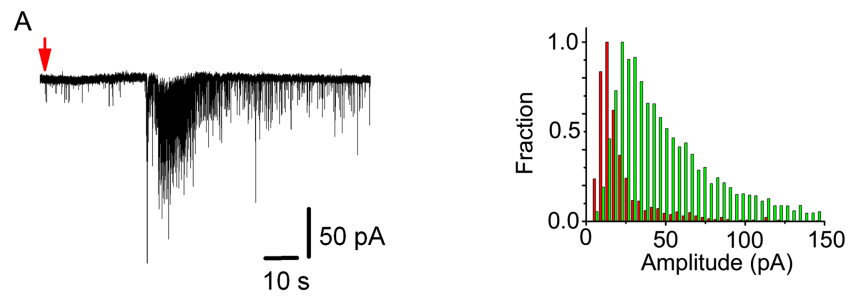

B
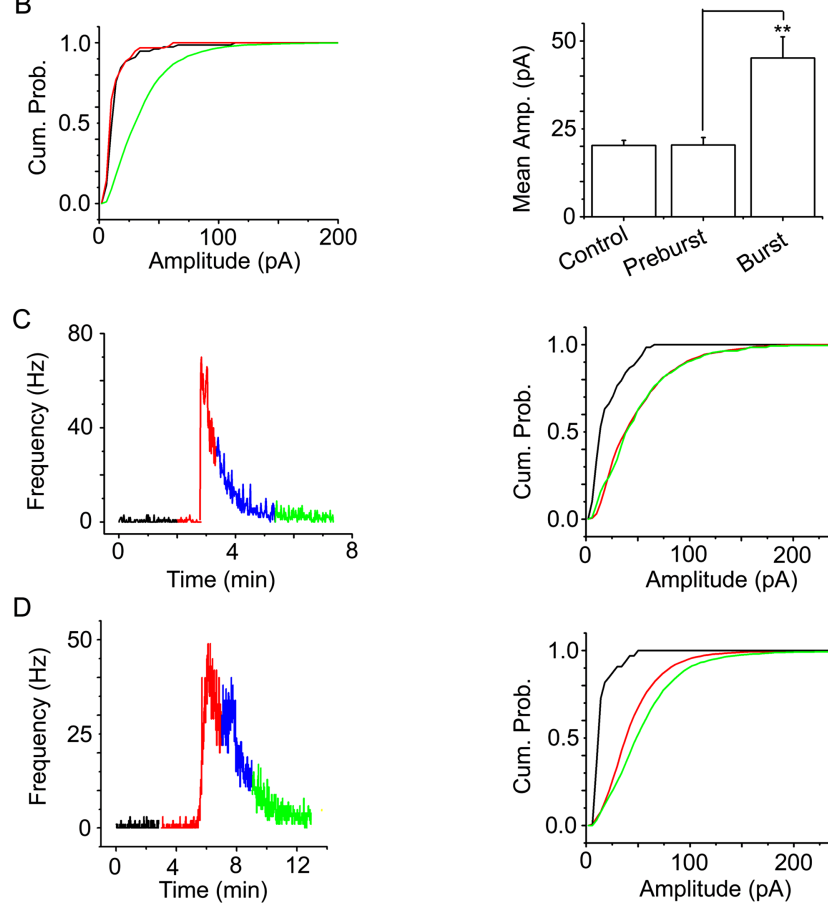

Figure 1. $n A C h R$ activation mediates burst of $m E P S C s$. $A$, Left, Current trace showing mEPSCs. A 120 s application of $20 \mu \mathrm{m}$ nicotine (at the red arrow) causes a delayed burst of mEPSCs. Right, The amplitude distribution shows a pronounced rightward shift of the entire distribution (green bars; $p<0.0001$ ) compared with control (red bars). $\boldsymbol{B}$, The onset of the amplitude shift coincides with the onset of the high-frequency burst. Left, Cumulative probability distribution under control conditions (black trace), in the intervening period between nicotine application and the onset of the burst (red trace), and during the burst (green traces). Right, Mean amplitudes from six cells. The mean amplitudes during the preburst period were not significantly different from that of controls ( $p=0.98$ ), whereas during the burst, the mean amplitudes were significantly larger compared with the preburst period $\left.{ }^{* *} p<0.01\right)$. C, Amplitude increase outlasts the frequency change. Left, Frequency response to the application of $20 \mu \mathrm{m}$ nicotine (period given by the red trace) followed by two periods of drug washout (blue and green). Nicotine causes a burst of high frequency that returns close to baseline after washout of the drug. Right, Cumulative probability distribution of amplitudes showing a distinct rightward shift (color codes same as for the left panel). The amplitude distribution is still shifted during the second wash period (green; $p<0.0001$ compared with control). $D$, The same experiment using $100 \mu \mathrm{m} \mathrm{ACh/At.} \mathrm{Left,} \mathrm{Frequency} \mathrm{change} \mathrm{before} \mathrm{(black} \mathrm{trace),} \mathrm{during} \mathrm{(red} \mathrm{trace),} \mathrm{and} \mathrm{after} \mathrm{wash}$ (blue and green traces). Right, Cumulative probability distribution of amplitudes (same color code) showing the long-lasting rightward shift in distribution after a prolonged washout of the $\operatorname{drug}(p<0.0001$ compared with controls).

the presence of $0.5 \mu \mathrm{M}$ atropine (ACh/At) (Fig. 1D). At 4-6 min after washout of the agonist, the amplitude distribution was still shifted to the right ( $p<0.0001$ compared with controls). During the wash period, the mean amplitude of the mEPSCs, from a number of experiments, was still elevated compared with the control ( $44 \pm 6.6 \mathrm{pA}$ vs $21.4 \pm 2.6 \mathrm{pA} ; n=12$ cells; $p<0.005$, paired $t$ test), although, on average, it was $79 \%$ of that seen during the mEPSC burst after agonist application $(p<0.01$, paired $t$ test). The duration of the high-frequency burst, defined as the period from onset to where the frequency falls below twice the peak control frequency, was $52 \pm 10 \mathrm{~s}$ (Sharma and Vijayaraghavan, 2003). The amplitudes remained significantly elevated over control at $p<0.05$ for $7.4 \pm 1 \mathrm{~min}$ (from12 cells; range 4-10 $\mathrm{min}$ ) after cessation of agonist application. The minimum concentrations of $\mathrm{ACh} / \mathrm{At}$ required to elicit the mEPSC burst lay between 10 and $100 \mu \mathrm{M}$ (data not shown). As both nicotine and $\mathrm{ACh} /$ At had the same effects on mEPSC frequencies and amplitudes, the two agonists were used interchangeably in this study.

The dissociation of amplitude and frequency motivated a further examination of the underlying mechanisms for regulating mEPSC amplitudes.

nAChR-mediated amplitude changes involve both AMPA and kainate receptors

In the presence of $10 \mu \mathrm{M} C N Q X$ and $50 \mu \mathrm{M}$ APV no events were seen confirming their glutamatergic nature (Sharma and Vijayaraghavan, 2003). nAChR-induced burst of mEPSCs were not elicited when the agonist was applied outside stratum lucidum, in the stratum radiatum consistent with the events being mossy fiber in origin (data not shown).

As inhibition of release by the mGluR type II agonist $\left(2 S, 2^{\prime} R, 3^{\prime} R\right)-2-\left(2^{\prime}, 3^{\prime}\right.$ dicarboxycyclopropyl)glycine (DCG-IV) has been used to determine mossy fiber origins of evoked responses, we tested its effects on the $\alpha 7-\mathrm{nAChR}$ mediated mEPSC bursts. Slices were preincubated with $10 \mu \mathrm{M}$ DCG IV for 10-15 min before agonist application. mEPSC bursts were still elicited with ACh/At application. The mean burst frequencies in the absence and presence of the $\mathrm{nAChR}$ agonist were $0.5 \pm 0.18 \mathrm{~Hz}$ and $14.5 \pm 1.4 \mathrm{~Hz}$, respectively $(n=4 ; p<0.002)$. The average peak frequency of the burst was $60 \pm 11 \mathrm{~Hz}$. The average mEPSC amplitude was $20 \pm 1 \mathrm{pA}$ in controls and $36 \pm 0.37 \mathrm{pA}$ with nAChR activation $(p<0.001)$. These data are consistent with our previous finding that VGCC blockers do not significantly affect the nAChR-induced burst (Sharma and Vijayaraghavan, 2003). DCG-IV has been shown to have a small ( $\sim 25 \%$ reduction) effect on mEPSC frequencies but not amplitudes (Kamiya and Ozawa, 1999). Such changes would not be apparent because of the inherent variation in the $\mathrm{AChR}$-induced bursts. What can be inferred from these experiments is that the DCG-IV sensitivity might not be a good indicator for the mossy fiber origin of mEPSCs.

In the absence of mGluR inhibition as a definitive criterion for determining mossy fiber origin, we took a different approach. We made use of the fact that spontaneous mossy fiber events, in addition to the AMPA component, have a significant contribution from kainate receptors (Cossart et al., 2002).

We first examined mEPSCs generated by $\mathrm{nAChR}$ activation in the presence of $100 \mu \mathrm{M}$ APV plus $10 \mu \mathrm{M}$ SYM2081 [(2S,4R)-4methyl glutamic acid; SYM] to isolate the AMPA component. This resulted in a fast current with a rise time of $1.66 \pm 0.12 \mathrm{~ms}$ and a mean decay time constant of $6.4 \pm 0.42 \mathrm{~ms}$ (Fig. $2 A, B)(n=$ $6)$, significantly faster than currents recorded in the presence of APV alone (Fig. $2 B)(p<0.05)$.

Application of ACh/At in the presence of $100 \mu \mathrm{M}$ APV plus 50 $\mu \mathrm{M}$ GYKI 53655 (GYKI), to isolate the KA component, also resulted in a pronounced increase in the frequency of slow mEPSCs with rise times of $5.97 \pm 0.49 \mathrm{~ms}$ and decay time constants of $46 \pm 5 \mathrm{~ms}$ (Fig. $2 A, B)(n=6)$.

Rise time versus decay plots showed a close clustering of the AMPA and the fast component of AMPA+KA currents. The KA component, however, formed a separate and distinct cluster, with no overlap, at the right-hand top corner of the graph (Fig. 2C). The kinetics of both AMPA and KA mEPSCs obtained by us were 
faster than that reported by Cossart et al. (2002), possibly because of differences in the composition of internal solutions (e.g., $1 \mathrm{~mm}$ EGTA vs $10 \mathrm{~mm}$ BAPTA). Our AMPAR kinetics are much closer to what has been reported at these synapses earlier (Jonas et al., 1993)

Subtracting averaged traces from APV alone currents from those treated with $\mathrm{APV}+\mathrm{SYM}$, derived from the same cells, resulted in a slow component that could be overlaid on averaged currents derived from APV + GYKI-treated cells (Fig. 2B) demonstrating that in the presence of APV alone, the mEPSCs had both an AMPA and a KA component.

These results suggest that the mEPSCs generated in the presence of $\mathrm{nAChR}$ agonists are mossy fiber in origin and not caused by activation of a different population of synapses.

We then characterized the largeamplitude mEPSCs obtained in response to nAChR activation to answer two questions: (1) are they mossy fiber in origin (i.e., do they contain a KA component) and (2) Do both components increase in the large mEPSCs?

We first divided mEPSCs into two groups: small $(<25 \mathrm{pA})$ and large $(>25$ $\mathrm{pA})$. Because the magnitude of the large events is mainly determined by the AMPA component, we averaged traces obtained in the presence of APV alone and APV plus SYM. The AMPA currents were subtracted from the total (APV alone) to generate the KA component. The charge transfer for the two components were calculated and expressed as a percentage of the total. The results are shown in Figure $2 \mathrm{D}$. The KA component for both small and large mEPSCs was significant accounting for $39 \pm$ $4.4 \%$ and $33 \pm 4 \%$ of the total charge transfer for small and large mEPSCs, respectively. The two components scaled proportionally to generate the large events $(p=0.3$; $n=6)$.

These results show that the large mEPSCs are mossy fiber in origin. Our data also suggest that these events arise from concerted neurotransmitter release rather than postsynaptic mechanisms as it is unlikely that there is a proportional insertion or modification of both receptor classes.

\section{Low temperature dissociates nAChR-mediated frequency and} amplitude changes

If the large-amplitude mEPSCs arise from concerted release, we argued that they should be slowed down, dissociated, or abolished by lowering the recording temperature, compared with room temperature (RT). Slices were bathed with cold ACSF to achieve a chamber temperature between 15 and $17^{\circ} \mathrm{C}$ [low temperature (LT)]. mEPSCs were recorded in the absence and presence of $100 \mu \mathrm{M}$ ACh/At. The control mEPSC frequency was $0.36 \pm 0.12 \mathrm{~Hz}$ compared with $1.2 \pm 0.4 \mathrm{~Hz}$ at RT (Sharma and Vijayaraghavan, 2003). High-frequency bursts were observed in
B

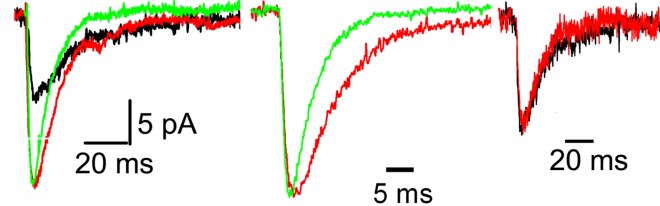

$20 \mathrm{pA}$

$200 \mathrm{~ms}$
C
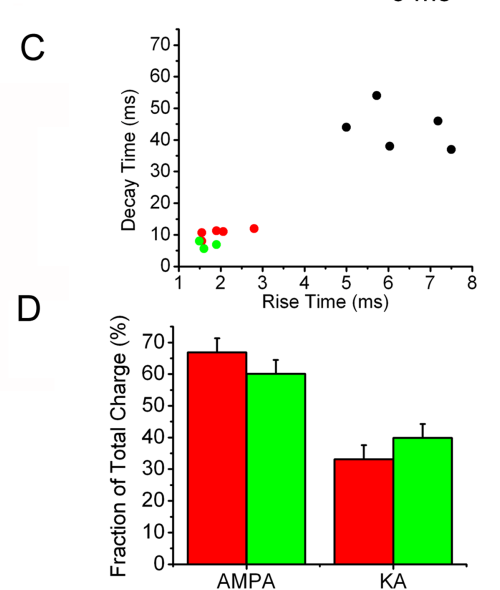

Figure 2. Large-amplitude mEPSCs are mossy fiber in origin. $A$, mEPSC burst elicited by $20 \mu \mathrm{m}$ nicotine in the presence of 100

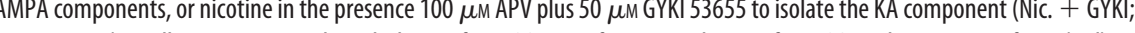
trace). In all cases, nicotine elicited a burst of mEPSCs. $\boldsymbol{B}$, Left, Averaged trace of $m E P S C s$ in the presence of APV (red), in in the presence of APV plus SYM. Middle trace, An averaged and normalized trace from APV-treated cells in the a component. Right trace, Normalized average KA component in the presence of GYKI 53655 (black trace) or obtained by subtract( (black). All events were fitted with a single exponential. The KA component showed a distinct cluster toward the right corner of the graph. $\boldsymbol{D}$, Fractional contributions of the AMPA and KA components. The KA component was derived by subtracting the graph. The KA component makes a significant contribution to the total current. There were no significant differences in the two components between large and small mEPSCs ( $p=0.3$; for both groups).

the presence of the agonist in all cases $(n=4)$ (Fig. $3 A, B)$. The average delay in onset of the burst was $62 \pm 13 \mathrm{~s}$ at LT $(p=0.078$; compared with $29 \pm 7 \mathrm{~s}$ at RT) (Sharma and Vijayaraghavan, 2003). The increase in frequency, in the presence of agonist was $7.5 \pm 2$-fold over the LT control, compared with $10.2 \pm 1.6$-fold at RT, compared with its control.

Interestingly, the amplitude distribution did not change significantly with ACh/At treatment at LT ( $p=0.1$ ) (Fig. 3C). The mean mEPSC amplitudes were $17.3 \pm 0.9 \mathrm{pA}$ for controls at LT ( $n=255$ mEPSCs from 4 cells) and $18.9 \pm 0.2 \mathrm{pA}$ during ACh/At bursts ( $n=3578 \mathrm{mEPSCs}$ ), not significantly different from each other ( $p=0.08$, unpaired $t$ test). The 95th percentile of the control amplitude distribution at LT was $37.4 \mathrm{pA}$. In the presence of the nAChR agonist, $7 \%$ of the events were above the 95th percentile of the control, compared with 33\% at RT (Sharma and Vijayaraghavan, 2003). The average amplitude of events above the 95 th percentile of control was $48.1 \pm 0.8 \mathrm{pA}$ at LT, compared with $91 \pm 0.7 \mathrm{pA}$ large events at RT ( $n=3$ cells, 247 and 3188 events for LT and RT, respectively; $p<0.0001$ ) (Fig. $3 D$ ). The average $10-90 \%$ rise time of the large-amplitude mEPSCs was 
A

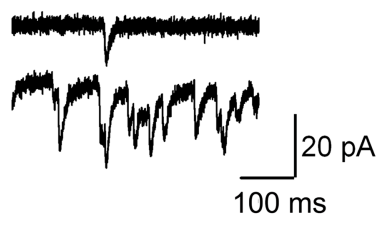

B

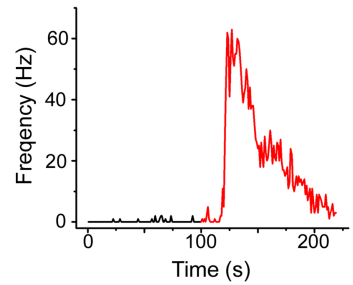

C

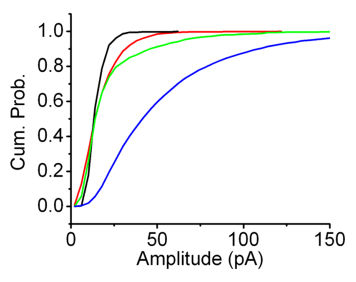

D

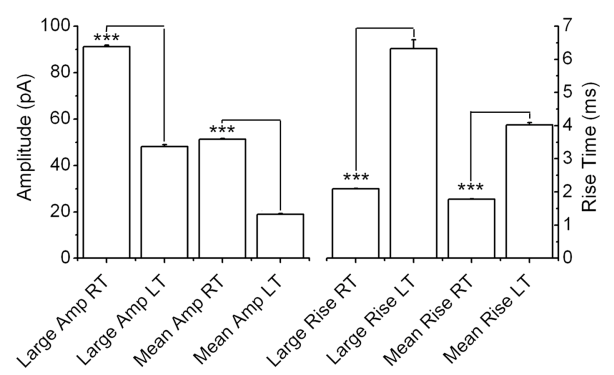

Figure 3. Low temperature dissociates high-amplitude events. $\boldsymbol{A}$, Responses to $100 \mu \mathrm{m} \mathrm{ACh} / \mathrm{At}$ recorded at $15-17^{\circ} \mathrm{C}(\mathrm{LT})$. $\mathrm{mEPSC}$ in control (top trace) and in the presence of agonist (bottom trace). $\boldsymbol{B}, \mathrm{mEPSC}$ frequency response in the absence (black trace) and the presence (red trace) of the agonist. Activation of nAChRs caused a robust increase in mEPSC frequencies. $\boldsymbol{C}$, Cumulative probability distribution of amplitudes in control (black trace), in the presence of ACh/At (red trace) at LT, and at RT $\left(23^{\circ} \mathrm{C}\right.$; green and blue traces respectively; data from 4 cells). The amplitude changes are abolished at LT ( $p=0.1$ control vs agonist), whereas a robust change is seen at RT ( ${ }^{* * *} p<0.0001$ control vs agonist). D, Amplitudes and $10-90 \%$ rise times at LT and RT for large ( $>95$ th percentile of respective controls) or averaged over all events. The amplitudes were significantly reduced $\left({ }^{* * *} p<0.002, \mathrm{RT}\right.$ vs $\left.\mathrm{LT}\right)$ and the rise times slower at $\mathrm{LT}\left({ }^{* * *} p<0.002, \mathrm{RT}\right.$ vs $\left.\mathrm{LT}\right)$.

A

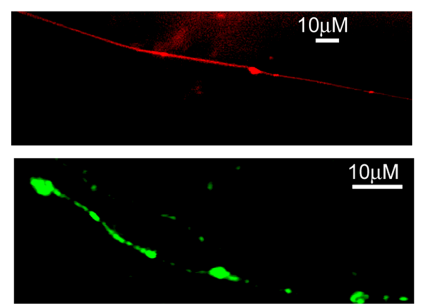

B

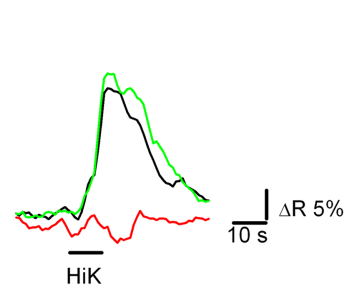

C

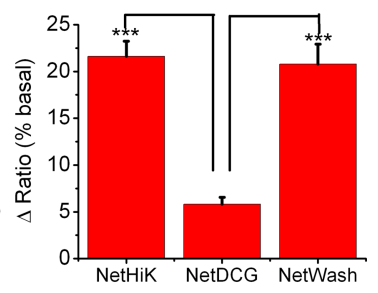

Figure 4. Imaging MFBs. A, Top, Dye I-labeled MFB showing a beaded morphology characteristic of these terminals. Bottom, MFBs loaded with Fura-2 AM B, Calcium transient in response to a 10 sapplication of $70 \mathrm{~mm} \mathrm{KCl} \mathrm{(HiK)} \mathrm{in} \mathrm{the} \mathrm{absence} \mathrm{(blacktrace)} \mathrm{or} \mathrm{presence} \mathrm{(red}$ trace) of $10 \mu \mathrm{mDCG}-\mathrm{IV}$. The mGluRagonist significantly attenuated the response compared with control. Washout of the agonist resulted in near complete recovery of the response (green trace). C, Average data from 15 boutons before (Net HiK), during (Net DCG), or after washout (Net wash) of the mGluRagonist. In the presence of $10 \mu \mathrm{m} \mathrm{DCG-IV}$, the calcium response was attenuated by $73 \pm 9 \%$ (*** $p<$ 0.0001 compared with both the first response and response upon washout of the drug).

$2.01 \pm 0.4 \mathrm{~ms}$ and $6.3 \pm 0.3 \mathrm{~ms}$ at RT and LT, respectively, and the mean rise time for all events was $1.78 \pm 0.01 \mathrm{~ms}$ and $4.0 \pm$ $0.06 \mathrm{~ms}$ for mEPSCs at RT and LT, respectively $(n=3$ cells, $p<$ 0.0001 RT vs LT for both) (Fig. 3D).

After visual examination of a total of 51 mEPSCs, that had amplitudes of $50 \mathrm{pA}$ or more, $94 \%$ of the events at low temperature showed distinct inflections in their rising phase (data not shown). Although this is consistent with concerted release, loss of most high-amplitude events at LT, and the lack of defined steps in amplitude along the rising phase of the mEPSCs, made additional analyses unlikely to yield any more useful information.

The loss of large-amplitude events at LT suggests that concerted release of multiple quanta is abolished at $15-17^{\circ} \mathrm{C}$. Coupled with the large increase in frequency observed, our data suggests that the release, for the most part, is desynchronized. Another interpretation of the results shown in this section is that at LT, the number of release events per unit time is not high enough to achieve concerted release of multiple quanta, perhaps because of the loss of an additional temperature sensitive step downstream of calcium required for synchrony. Consistent with this conclusion, the rate of charge transfer at LT (quanta/s) was $23 \pm 15 \%$ of that seen at RT $(n=4 ; p<0.02)$.

Our results thus far demonstrating decoupling of frequency and amplitude speak to the possibility that the amplitude change evoked by nAChRs requires an additional step downstream of calcium release from ER. The first step toward addressing this issue would be to demonstrate that $\alpha 7$ $\mathrm{nAChRs}$ indeed raise presynaptic calcium at MFBs.

\section{$\alpha 7-\mathrm{nAChR}$ activation causes a rise in calcium at MFBs}

Although our results and those of one previous work (Gray et al., 1996) suggest that presynaptic $\alpha 7$-nAChRs increase glutamate release from MFBs, the ability of these receptors to increase intraterminal calcium is controversial (Gray et al., 1996; Vogt and Regehr, 2001). We, therefore, re-examined whether cholinergic agonists increased calcium in MFBs using fura-2, the calcium dye used in both previous studies. The identity of MFBs was confirmed by their location (in stratum lucidum), size ( $\geq 2$ $\mu \mathrm{m})$, and in some cases by double labeling with Dye I (see Materials and Methods) (Figs. 4A, 5A). Additional confirmation was obtained by demonstrating that a $10 \mathrm{~s}$ pulse with $70 \mathrm{mM} \mathrm{KCl}$ (substituted for $\mathrm{NaCl}$ in the ACSF) produced a calcium transient that was blocked by preincubating the slice with $10 \mu \mathrm{M}$ DCG-IV (Fig. 4B). In the presence of DCG-IV the calcium response was decreased $73 \pm 9 \%(n=15$ boutons, $p<0.0001$ paired $t$ test) (Fig. $4 C$ ). Washing out the agonist resulted in a recovery of the response to $96 \pm 10 \%$ of the first response $(n=15 ; p=0.6$, paired $t$ test $)$

(Fig. $4 B$ and 4 C).

A $30 \mathrm{~s}$ application of $100 \mu \mathrm{M} \mathrm{ACh} / \mathrm{At}$, resulted in a calcium transient with a slow rising phase and long-lasting increase in $[\mathrm{Ca}]_{\mathrm{i}}$ in MFBs. Because of the slow calcium transient, area of the signal over a 100-200 s period (the relevant time for the mEPSC experiments) was a more accurate estimate of the magnitude of the calcium response than the peak response (taking the peak did not qualitatively change the results). In all cases, at the end of the experiment, a response to a $10 \mathrm{~s}$ application of $70 \mathrm{~mm} \mathrm{KCl}(\mathrm{HiK})$ was elicited to check the health of the terminals. Only terminals that responded with a calcium transient with $\mathrm{ACh} / \mathrm{At}$ that came back to baseline, and responded to HiK with a sharp transient, at the end of each experiment, were used for analyses.

In the presence of $10 \mu \mathrm{M}$ 1-(5-chloro-2,4-dimethoxyphenyl)-3-(5-methyl-isoxazol-3-yl)-urea (PNU-120596) (Hurst et al., 2005), the positive allosteric modulator for $\alpha 7$-nAChRs, the calcium response was much larger and therefore more reliable. 
Responses were $3.6 \pm 0.23$-fold greater than that in the absence of the modulator $(p<$ 0.0001 , paired $t$ test; $n=17$ boutons). The allosteric modulator was included in all further experiments. The ACh/At response was not a movement artifact as previously suggested (Vogt and Regehr, 2001) as we used ratiometric measurements and the response from $340 \mathrm{~nm}$ excitation and the $380 \mathrm{~nm}$ excitation were in opposite directions, as expected (Fig. 5D, left). The response was confirmed to be mossy fiber in origin by double labeling the boutons with Fura 2-AM and DiI (placed in the granule cell layer) (Fig. 5A, left). The double labeled cells gave an identical response to the application of $\mathrm{ACh} / \mathrm{At}$ and high potassium as those labeled with Fura 2 alone ( $n=10$ boutons) (Fig. $5 A$, middle, right).

A second response to the agonist elicited after 15-30 min wash was not significantly different from the first $(87 \pm 8.6 \%$; $p=0.2$, paired $t$ test; $n=21$ boutons). The response was due to activation of $\alpha 7-\mathrm{nAChR}$ as preincubating the cells with $125 \mathrm{nM} \alpha \mathrm{BTX}$ blocked the response. In the presence of the toxin, the ACh/At response was decreased by $84 \pm 16 \%$ compared with the controls ( $n=21$ boutons; $p<0.0001$, paired $t$ test) (Fig. $5 B, D$ right).

Treating the slice with $100 \mu \mathrm{M}$ ryanodine significantly reduced the ACh/At response. In the presence of ryanodine the ACh/At response was reduced to $61 \pm 5.1 \%(n=27$; $p<0.0001$ compared with controls, paired $t$ test) (Fig. 5C,D right), demonstrating that ER calcium stores contribute to the nAChR response in MFBs.

Our data clearly demonstrate a slow calcium transient in the MFBs, triggered by the activation of $\alpha 7$-nAChRs.

\section{Amplitude changes in response to sucrose elicited release}

The question raised by the calcium experiments is whether a rise in intraterminal calcium is sufficient to cause changes in mEPSC amplitudes. We argued that if it were so, transmitter release induced downstream of calcium release, using hypertonic sucrose, should be immune to nAChRmediated changes in amplitude. We, therefore, asked whether the long-lived changes in amplitude after nAChR activation could alter the amplitude distribution of responses to the application of $100 \mathrm{~mm}$ sucrose.

Application of sucrose by itself (for $30 \mathrm{~s}$ ) to the stratum lucidum elicited a burst of mEPSCs (Fig. 6A). The increase in frequency was variable with a mean peak frequency of $26 \pm 8.8 \mathrm{~Hz}(n=7$ cells) (Fig. $6 B)$ and the mean frequency averaged over the application period was $9.7 \pm 3.2 \mathrm{~Hz}$. However, the amplitude distribution was not significantly altered in the presence of sucrose (control vs sucrose,

A

B
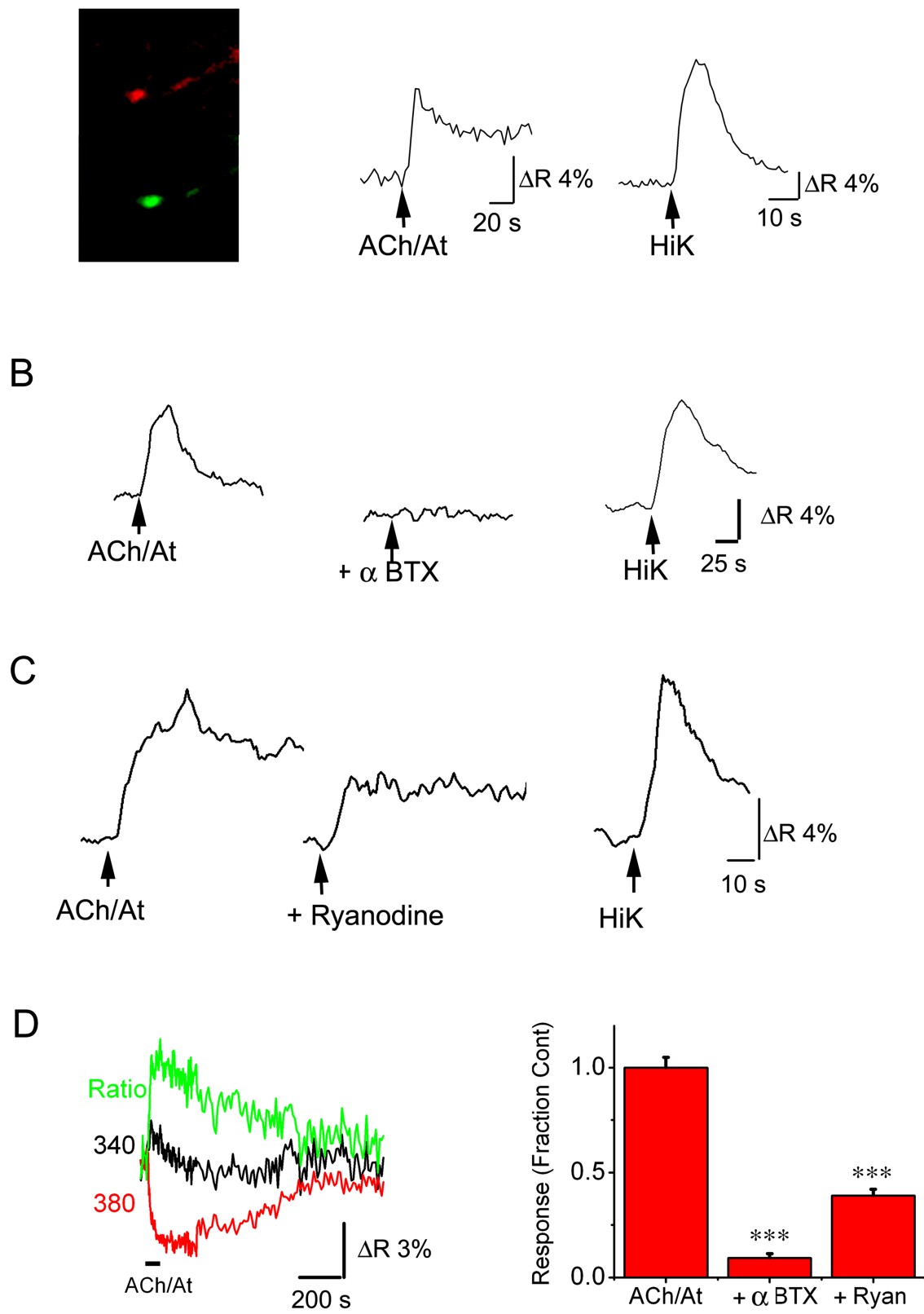

Figure 5. Calcium response to $\alpha 7$-nAChR activation. $A$, Left, A single MFB double labeled with Dye I (red) and Fura-2 (green). Middle trace, Response from this bouton to a $30 \mathrm{~s}$ application of $100 \mu \mathrm{m} \mathrm{ACh/At.} \mathrm{Right} \mathrm{trace,} \mathrm{Response} \mathrm{to} \mathrm{a} 10 \mathrm{~s}$ application of $70 \mathrm{~mm} \mathrm{KCl}$ from the same bouton. nAChR activation caused a slow long-lasting transient compared with the potassium application. $\boldsymbol{B}$, Response to $100 \mu \mathrm{m} \mathrm{ACh} / \mathrm{At}$ (left trace), to agonist application after a 30 min exposure to $125 \mathrm{~nm}$ $\alpha \mathrm{BTX}(+\alpha \mathrm{BTX}$; middle trace), and to a 10 s application of $70 \mathrm{~mm} \mathrm{KCl}$ (HiK; right trace). C, Control response to $100 \mu \mathrm{m} \mathrm{ACh/At}$ (left trace; $\mathrm{ACh} / \mathrm{At}$ ); response after a $30-50$ min incubation with $100 \mu \mathrm{m}$ ryanodine (middle trace; + Ryanodine) followed by a response to a $10 \mathrm{~s}$ application of KCI (third trace; HiK). $\boldsymbol{D}$, Left trace, Data from a single bouton to a $30 \mathrm{~s}$ application of $100 \mu \mathrm{M}$ ACh/At showing emission from $340 \mathrm{~nm}$ excitation (black trace), $380 \mathrm{~nm}$ excitation (red trace), and the 340/380 ratio (green trace). Boutons were imaged at $0.3 \mathrm{~Hz}$ for the first $100 \mathrm{~s}$ and $0.1 \mathrm{~Hz}$ for the subsequent period. Activation of nAChRs elicited a slow calcium transient demonstrating changes in the opposite directions for the $340 \mathrm{~nm}$ and the $380 \mathrm{~nm}$ response, ruling out movement artifacts. Bar graph, Attenuation of ACh/At response by a 30 min preincubation with $125 \mathrm{~nm} \alpha \mathrm{BTX}(+\alpha \mathrm{BTX})$ and a 45 min preincubation with $100 \mu$ m ryanodine (+Ryan). In the presence of the $\alpha 7$-nAChR antagonist, the calcium response was attenuated by $84 \pm 16 \%\left(n=21\right.$ boutons; ${ }^{* * *} p<0.0001$ compared with the ACh/Atresponse). The block of RyRs attenuated the $n A C h R$ response by $61 \pm 5.1 \%$ ( $n=27$ boutons; ${ }^{* * *} p<0.0001$ compared with control response).

$p=0.10$ ) (Fig. 6C) (308 and 3464 events, respectively). The mean amplitude in the presence of sucrose was also not significantly different from that of control mEPSCs $(24.1 \pm 1.3 \mathrm{pA}$ vs $22 \pm 1 \mathrm{pA} ; p=$ 0.2 , paired $t$ test; $n=6$ cells). This implies that changes in mEPSC 
A
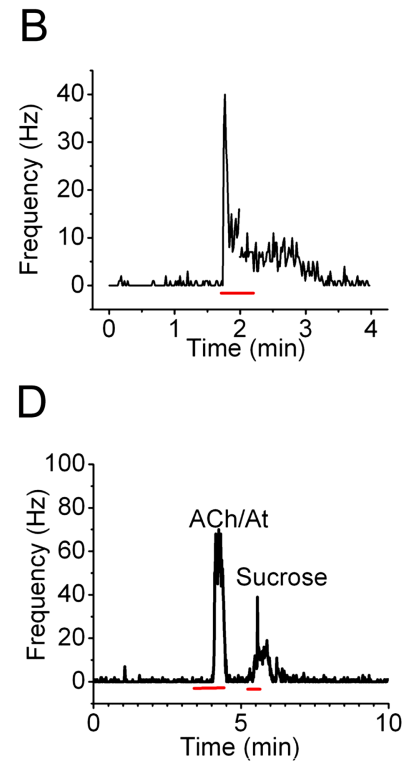

$\mathrm{F}$

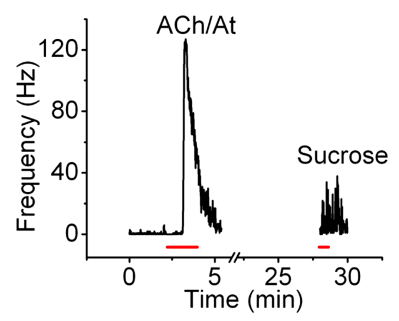

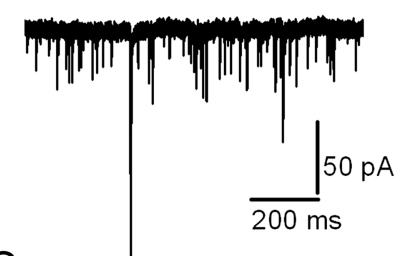

C

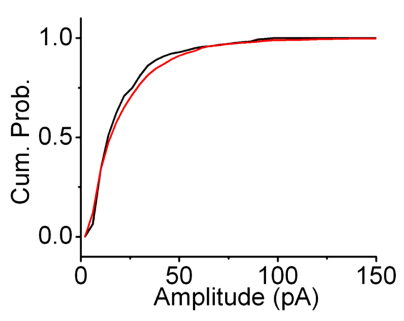

$E$

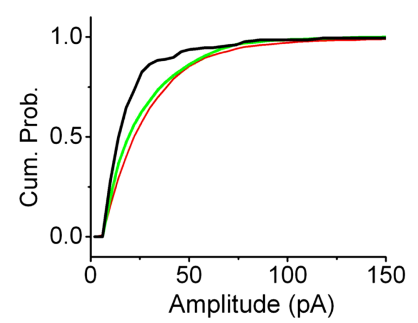

G

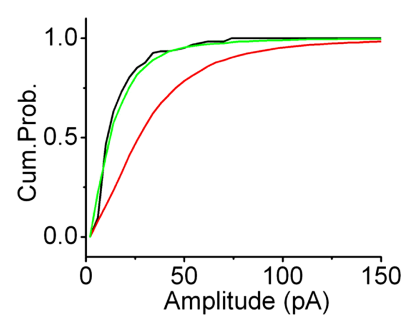

Figure 6. Amplitude changes are preserved during sucrose application after nAChR activation. $A$, mEPSCs before (left) and during (right) application of $100 \mathrm{~mm}$ sucrose. A distinct increase in $\mathrm{mEPSC}$ frequency was observed. $\boldsymbol{B}$, Frequency changes in the presence (red bar) of a $30 \mathrm{~s}$ application of sucrose. Sucrose elicited a burst of mEPSCs at high frequency. $\boldsymbol{C}$, Cumulative probability distribution of mEPSC amplitudes taken from six cells. No significant shift in the amplitude distribution was observed (control, black; sucrose, red; $p=0.19$ ). $\boldsymbol{D}$, Frequency changes in the presence of ACh/At (first red bar), followed by a $30 \mathrm{~s}$ application of $100 \mathrm{~mm}$ sucrose (second red bar). Sucrose still elicited an increase in $\mathrm{mEPSC}$ frequencies. $\boldsymbol{E}$, Cumulative probability distribution of amplitudes taken from six cells during control (black), during the period immediately preceding the sucrose application (green), and during sucrose application (red). Application of sucrose still elicited a rightward shift in the amplitude distribution, $p<$ 0.0002 compared with control; $p<0.07$ compared with the wash period after agonist application. $\boldsymbol{F}$, Frequency changes in response to ACh/At followed by $100 \mathrm{~mm}$ sucrose application 25 min later. A distinct burst of mEPSCs were observed in the presence of sucrose. $\mathbf{G}$, Cumulative probability distribution of amplitudes for control (black), ACh/At (red), and sucrose (green). Amplitude distributions in response to sucrose application 25 min later were not significantly different from that of the controls ( $n=3$ cells; $p=0.89$ compared with control; $p<0.0001$ compared with $\mathrm{ACh} / \mathrm{At}$ ).

frequencies alone are not sufficient to shift the amplitude distribution as would be predicted from previous data in this study.

We then asked whether the amplitude distribution after sucrose application would be altered if it immediately followed nAChR activation. Sucrose was applied for $30 \mathrm{~s}$ after the frequency changes induced by $\mathrm{nAChR}$ activation returned close to

baseline as estimated by eye, online. This necessitated the application of sucrose at different time points after the cessation of agonist application. We, therefore, followed the following protocol for analyses. The period during sucrose application where the mEPSC frequency exceeded twice the frequency in the preceding wash period was used to calculate amplitudes of sucrose-elicited events. A $20 \mathrm{~s}$ period immediately preceding sucrose application was taken to estimate baseline frequency. The same number of events as elicited by sucrose application was taken from the immediately preceding period and were used for comparison. If sucrose application did not elicit large-amplitude mEPSCs, we would expect to see a significant reduction in the mean amplitudes of the events and a shift in the amplitude distribution to the left of that seen from the preceding time period.

The results are shown in Figure 6. Sucrose application after the ACh/At application still raised mEPSC frequencies (Fig. 6D). The mean baseline frequency during the period immediately preceding sucrose application was $1.75 \pm 0.6 \mathrm{~Hz}$ and the mean frequency in the presence of sucrose was $6 \pm 1.8 \mathrm{~Hz}(n=6$ cells $)$.

The cumulative probability distribution of amplitudes of the mEPSCs, however, was still significantly shifted to the right compared with control (Fig. 6E) ( $p<0.0002,5264$ and 297 events, respectively). The distribution was not significantly different from that during the preceding period after nAChR activation $(p=0.07)$. The mean amplitude when sucrose was applied after ACh/At was $32 \pm 0.3 \mathrm{pA}$ (compared with $21 \pm 1 \mathrm{pA}$ for control mEPSCs and $34 \pm 0.6 \mathrm{pA}$ in the period immediately preceding sucrose application; $p<0.001$ compared with controls).

We also measured sucrose responses 20-25 min after the cessation of agonist application (Fig. $6 F, G$ ). There were no significant differences between sucrose mEPSCs and control mEPSCs in mean amplitudes $(19 \pm 0.4 \mathrm{pA}$ and $17 \pm 0.8 \mathrm{pA} ; p=0.82)$ or in the amplitude distribution ( $p=0.165 ; n=3$ cells). The percentage of sucrose events above the 95th percentile of control distribution was $5 \pm 1.2 \%$. Thus, it appears that nAChRmediated potentiation of sucrose responses does not outlast amplitude changes induced by agonist application.

The maintenance of high-amplitude events, when sucrose was applied after nAChR activation, suggests that the change in mEPSC amplitudes is caused by modulation by mechanisms downstream of ER calcium release.

Role of CaMKII in amplitude changes after nAChR activation The idea that the store calcium-dependent amplitude increases might occur downstream of ryanodine receptor (RyR)-activated increases in $[\mathrm{Ca}]_{\mathrm{i}}$ suggested to us that there might be additional effectors mediating the amplitude change. It has been reported that protein kinase $\mathrm{C}$ alters the frequency of release events seen after sucrose application at the calyx of Held (Wu and Wu, 2001). PKC has been shown to both increase the size of the readily releasable pool (RRP) of vesicles, as well as increase the rate of refilling in hippocampal neurons (Stevens and Sullivan, 1998), suggesting that protein kinase activity can regulate sucrose responses. We, therefore, asked whether protein phosphorylation might play a role in mediating the amplitude changes.

nAChRs have been shown to increase the activity of CaMKII (Tsutsui et al., 1996; Tang et al., 1998; Nakayama et al., 2001; Yamashita and Isa, 2003; Damaj, 2007) and, in the few cases tested, this occurs downstream of nAChR-mediated store calcium release (Chang and Berg, 2001; Hu et al., 2002). We, therefore, tested the role of CaMKII in modulating nAChR effects at MFBs. Slices were incubated with $10 \mu \mathrm{M}$ KN-93, a selective CaMK inhibitor, or with its negative analog, KN-92, using identical con- 
ditions (45-60 min incubation in the drug). KN-93 completely blocked amplitude changes while maintaining the highfrequency burst (Fig. $7 A, B$ ). The peak frequency in the presence of KN-93 was $45.4 \pm 11 \mathrm{~Hz}(n=10$ cells) compared with agonist alone $(45.3 \pm 4.5 \mathrm{~Hz} ; n=6 ; p=0.99)$. In the presence of $\mathrm{KN}-93$, the cumulative probability distribution of amplitudes and the mean amplitudes were not significantly different from control values ( $p=0.55$ and 0.75 , respectively) (Fig. $7 B, D)(1425$ events control; and 9633 events KN-93). The mean amplitude of control mEPSCs in the presence of KN-93 was $22 \pm 1.2 \mathrm{pA}$, not significantly different from untreated controls $(p=0.4,234$ and 239 events, respectively; data from same cells) and the basal frequency in the presence of $\mathrm{KN}-93$ was $85 \pm 5 \%$ of controls before treatment from the same cells ( $p=0.7$, paired $t$ test, $n=2$; data from same cells).

The application of agonist in the presence of $10 \mu \mathrm{M} \mathrm{KN}-92$, the inactive analog as a negative control, had effects on frequencies not significantly different compared with either the agonist alone or agonist in the presence of KN-93 (Fig. 7C) (mean frequency, $46.25 \pm 9.06 \mathrm{~Hz}, n=8 ; p=0.95$ compared with agonist in the presence of $\mathrm{KN}-93 ; p=0.96$ compared with agonist alone). Unlike with the active analog, the amplitude distribution in KN-92 was significantly shifted to the right (Fig. $7 C)(p<0.0001 \mathrm{com}-$ pared with both control and agonist in the presences of KN-93). Our results suggest that active CaMKII is required for the concerted release of multiple quanta induced by nAChR activation, but not the induction of the high-frequency burst.

The availability of an inactive analog makes KN-93 the main, reliable, membrane-permeant CaMKII inhibitor. KN-92, the inactive form, mimics all effects of KN-93 with the exception of its ability to inhibit kinase activity. For this reason, it has often been used as the sole inhibitor for implicating CaMKII (Fog et al., 2006). Shared nonspecific effects of all membrane-permeant CaMKII inhibitors ( $\mathrm{Li}$ et al., 1992; Tsutsui et al., 1996) makes their effects hard to interpret without a negative control. Therefore, instead of testing a second CaMKII inhibitor, constrained by the same caveats, we chose to test the involvement of other calcium and/or CaM-dependent kinases known to affect transmitter release (Stevens and Sullivan, 1998; Wu and Wu, 2001; AriasMontano et al., 2007). At the CA3-mossy fiber synapse multiple kinases have been shown to alter transmitter release probabilities. In addition to CaMKII (Salin et al., 1996), these are protein kinase A (PKA) (Goussakov et al., 2000; Mellor et al., 2002) and PKC (Galimberti et al., 2006).

We used protein kinase inhibitors with selectivities for PKA (100 $\mu \mathrm{M} \mathrm{H}-89)$ and PKC (100 $\mu \mathrm{M}$ bisindolylmaleimide). Slices were exposed to all antagonists for a period of 45-60 min before recording, to ensure their loading.

There was no effect of blocking PKA and PKC using their respective inhibitors at 10-100 times the concentrations shown to be effective in blocking transmitter release from presynaptic terminals in acute slices (Wu and Wu, 2001; Xu et al., 2004; Asaumi et al., 2006; rias-Montano et al., 2007). Results are shown in supplemental Figure 1 (available at www.jneurosci.org as supplemental material)

Because KN-93 is a membrane permeant antagonist, we could not use it in the patch pipette to rule out postsynaptic contributions. Instead we included $1 \mu \mathrm{M}$ autocamtide- 2 related inhibitory peptide (AIP) which is 25 times its IC $_{50}$ for inhibiting CaMKII (Ishida et al., 1995), in the patch pipette. The peptide was allowed to diffuse for 30-40 min before agonist application. AIP had no effect on nAChR-mediated frequency or amplitude changes ( $n=$ 6 cells) (supplemental Fig. 2, available at www.jneurosci.org as

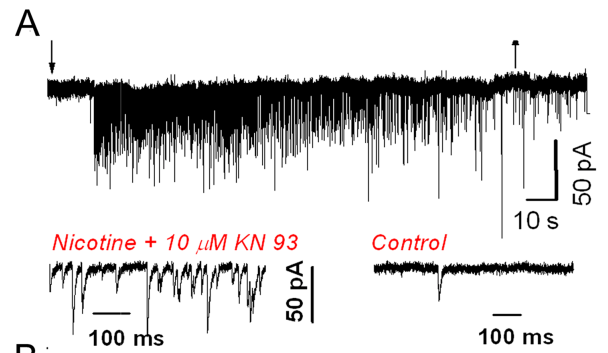

B
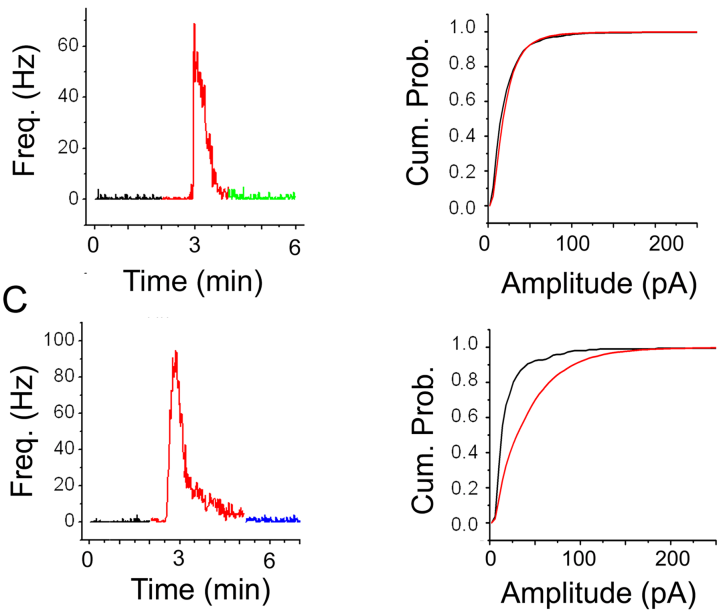

D

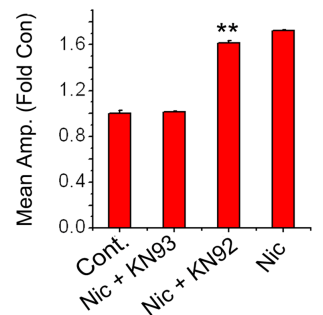

$E$

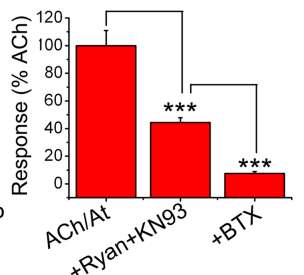

Figure 7. CaMKIl antagonist abolishes amplitude changes. $A$, Nicotine $(20 \mu \mathrm{m})$ elicited an mEPSC burst in the presence of $10 \mu \mathrm{m}$ KN-93. The CaMKII antagonist was incubated for 45 min before agonist application. Bottom traces, Expanded traces for nicotine and control in the presence of KN-93. B, Left, Frequency changes in the presence of KN-93 in a single cell (control, black; nicotine, red; and wash, green). Nicotine ( $20 \mu \mathrm{m}$ ) elicited a robust burst of high-frequency mEPSCs. Right, Cumulative probability distribution of amplitudes for control (black traces) and $n A C h R$ activation in the presence of KN-93 from seven cells (red trace). The shift in the amplitude distribution was not significant ( $p=$ 0.55). C, Left, Frequency changes after application of $20 \mu \mathrm{m}$ nicotine after a 45 min incubation with 10 $\mu \mathrm{m}$ of the inactive analog KN-92 (control, black; nicotine, red; wash, blue). KN-92 elicited a robust increase in mEPSC frequencies. Right trace, Cumulative probability distribution of amplitudes in the absence (black trace) and in the presence (red trace) of $20 \mu \mathrm{m}$ nicotine plus $10 \mu \mathrm{m} \mathrm{KN}-92$ from six cells. The agonist elicited a robust shift in the amplitude distribution in the presence of the inactive analog $\left({ }^{* *} p<0.001\right.$ ). D, Mean mEPSC amplitude for control, $20 \mu \mathrm{m}$ nicotine plus $10 \mu \mathrm{m}$ KN-93 (Nic + KN93), nicotine in the presence of $10 \mu \mathrm{M} \mathrm{KN-92} \mathrm{(Nic.} \mathrm{+} \mathrm{KN92),} \mathrm{or} \mathrm{nicotine} \mathrm{alone} \mathrm{(Nic).} \mathrm{In} \mathrm{the} \mathrm{presence}$ of the active CaMKII inhibitor, the mean amplitudes after nicotine application were not significantly different from the control ( $p=0.8$, whereas in the presence of the inactive analog, a significant increase in $\mathrm{mEPSC}$ amplitudes was observed (44.4 $\pm 0.5 \mathrm{pA} ; p<0.0001$ compared with control). $\boldsymbol{E}$, Calcium responses in the presence of KN-93. Left, Calcium trace from a single bouton showing responses to ACh/At (black); $\mathrm{ACh} / \mathrm{At}+100 \mu \mathrm{m}$ ryanodine $+10 \mu \mathrm{m}$ KN-93 (red); and ACh/At + KN-93 + ryanodine $+125 \mathrm{~nm}$ $\alpha \mathrm{BTX}$ (green). Middle, HiK response from the same bouton elicited at the end of the experiment. Right, Cumulative data from 16 boutons. Inhibition of ACh/At signals after treatment with KN-93+ ryanodine was highly significant ${ }^{* * *} p<0.0001$, paired $t$ test), as was the further inhibition of the signal by $\alpha \mathrm{BTX}\left({ }^{* * *} p<0.0001\right.$, paired $t$ test). The magnitude of the signal in the presence of ryanodine and KN-93 was not significantly different from that with ryanodine alone (Fig. 5) ( $p=0.49$ ). 
A

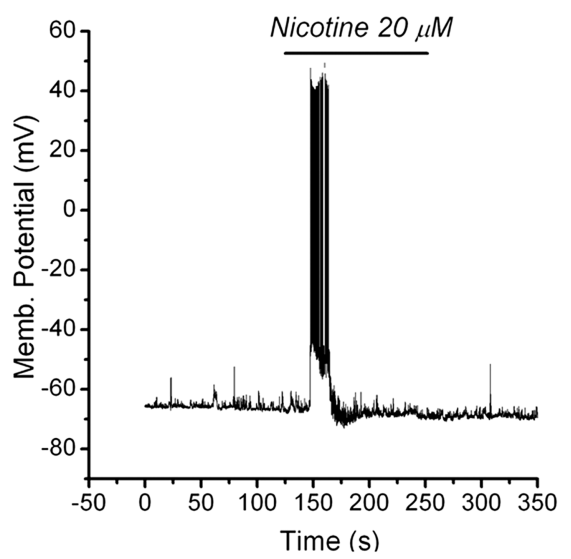

B

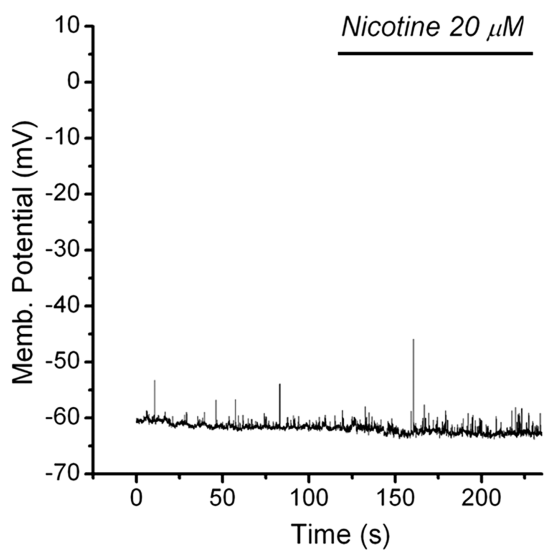

Figure 8. Inhibition of CaMKII abolishes postsynaptic firing. $\boldsymbol{A}$, Response of a CA3 pyramidal cell to the application of $20 \mu \mathrm{M}$ nicotine under current-clamp mode. Application of the agonist caused a delayed burst of APs concomitant with the burst of high-frequency mEPSCs. B, Same experiment in cells treated for 45 min with $10 \mu \mathrm{M} \mathrm{KN}-93$. Although one could observe increased number of mEPSPs, no postsynaptic firing was observed.

supplemental material). The mean amplitude of the mEPSCs in the presence of AIP was $48.26 \pm 0.195 \mathrm{pA}(n=6)$ whereas that with agonist alone was $47.5 \pm 0.3 \mathrm{pA}(n=3)$, not significantly different from each other $(p=0.21)$.

As the postsynaptic effects of CaMKII block have not been well characterized at the mossy fiber-CA3 synapse, a definitive positive control for the AIP experiment was not possible. We used a second approach to confirm the presynaptic locus of action. It has been shown that inclusion of $10 \mathrm{~mm}$ BAPTA in the patch pipette abolishes or drastically attenuates store calciummediated postsynaptic alterations during multiple forms of mossy fiber LTP (Yeckel et al., 1999). In addition, inclusion of the buffer abolishes ER store-dependent calcium changes in CA3 dendrites. These results suggest that BAPTA reaches the postsynaptic thorny excrescences and should abolish ER storedependent changes at postsynaptic sites.

As the changes in mEPSC amplitudes are entirely dependent on store calcium (Sharma and Vijayaraghavan, 2003), we argued that inclusion of $10 \mathrm{~mm}$ BAPTA in the pipette should abolish nAChR-mediated amplitude changes if they were postsynaptic in origin. Results are shown in supplemental Figure $2 D$ (available at www.jneurosci.org as supplemental material). A period of 30-40 min was given before testing for agonist response, to ensure adequate diffusion of the buffer. Application of agonist in the presence of BAPTA caused a robust increase in both mEPSC frequencies and amplitudes clearly demonstrating the presynaptic origins the amplitude response.

Does the KN-93 effect come from a direct inhibition of presynaptic $\alpha 7$-nAChRs? To obtain evidence for or against this possibility, we examined ACh/At-induced changes in $[\mathrm{Ca}]_{\mathrm{i}}$ at MFBs under conditions where store contributions were blocked by 100 $\mu \mathrm{M}$ Ryanodine (see Fig. 5). Incubation with Ryanodine and 10 $\mu \mathrm{M} \mathrm{KN}-93$ decreased the fluorescence changes to $55.7 \pm 4.3 \%$ of the control ACh/At responses from the same cells (Fig. 7E) $(n=$ 16 boutons; $p<0$. 0.0001 , paired $t$ test). The residual signal was further blocked by $125 \mathrm{nM} \alpha \mathrm{BTX}(7.5 \pm 1.5 \%$ of ACh/At alone; $p<0.0001$ compared with signals from agonist alone and agonist plus ryanodine plus $\mathrm{KN}-93$; paired $t$ test). Interestingly, the agonist-induced signal in the presence of KN-93 and Ryanodine was not significantly different from that in the presence of Ryanodine alone (55.7 and $61.5 \%$ of responses to agonist alone, re-

spectively, $p=0.4$, unpaired $t$ test). These results suggest that if the residual calcium signals, after blocking store contributions with $100 \mu \mathrm{M}$ ryanodine, were caused by calcium flux through $\alpha 7$-nAChRs, KN-93 had no significant effect on the receptor.

\section{Both amplitude and frequency changes are required for $\mathrm{nAChR}$-mediated postsynaptic firing}

Our previous work (Sharma and Vijayaraghavan, 2003) showed that the onset of the high-frequency and -amplitude burst leads to postsynaptic firing. Our data suggest that the postsynaptic firing occurs only at the initial burst period when the frequency and amplitude changes are maximal. The average duration of postsynaptic firing was $18 \pm 9 \mathrm{~s}(n=7$; compared with the mean duration of the mEPSC burst, $52 \pm 10 s ; p<0.02)$. No changes in mEPSP frequencies were observed before the burst of APs. This is consistent with the finding that there is no change in mEPSC frequencies before the burst as well (Fig. 1). As both frequency and amplitude changes require release of store calcium (Sharma and Vijayaraghavan, 2003), it is possible that the spatial localization of the $\alpha 7$-nAChRs on MFBs is such that flux through the channel does not cause sufficient changes in $[\mathrm{Ca}]_{\mathrm{i}}$ near exocytic sites to affect release. This interpretation would be consistent with our previous finding in another system where detected calcium signals after receptor activation were entirely attributable to receptor-mediated store calcium release (Sharma and Vijayaraghavan, 2001).

Our previous data also suggested that at low frequencies, large-amplitude events were not sufficient to drive the pyramidal neuron above threshold. Here we asked whether the initial highfrequency burst was sufficient to drive postsynaptic firing.

Nicotine $(20 \mu \mathrm{M})$ was applied at the stratum lucidum and the membrane voltage monitored in the current clamp mode. The agonist elicited a burst of APs (Fig. 8A) after a delay of $38 \pm 12 \mathrm{~s}$; $n=7$ (compared with the mEPSC burst delay of $29 \pm 7 \mathrm{~s} ; p=$ 0.53 ). This was accompanied by a rightward shift in the mEPSP amplitude distribution.

In cells that were incubated with $10 \mu \mathrm{M} \mathrm{KN}-93$, although one could observe an increase in the number of mEPSPs, no postsynaptic firing was seen (zero of five cells) (Fig. $8 \mathrm{~B}$ ). These results demonstrate that both an increase in the number of release events, as well as the concerted release of multiple quanta is required to drive the postsynaptic cell above threshold. The CaMKII inhibitor did not alter the AP-threshold or mEPSP kinetics (supplemental text and Fig. 3, available at www.jneurosci.org as supplemental material).

We then calculated the frequency of release required to elicit postsynaptic firing. To do this we estimated the charge carried by a uniquantal mEPSCs. Averaging 1363 fast mEPSCs (10-90\% rise times $\leq 1.5 \mathrm{~ms}$ ) with amplitudes $<20 \mathrm{pA}$, the mean amplitude under control conditions, as shown previously (Sharma and Vijayaraghavan, 2003) gave a relatively homogenous population (coefficient of variation, 19\%) of unitary mEPSCs with a mean amplitude of $15 \pm 0.1 \mathrm{pA}$, mean $10-90 \%$ rise time of $0.95 \pm$ $0.008 \mathrm{~ms}$, and a mean charge of $65 \pm 5 \mathrm{fC}$; comparable with that reported earlier at these synapses (Jonas et al., 1993). There was no positive correlation between rise times and amplitudes among 
these mEPSCs $(r=-0.003 ; p=0.911)$ arguing against these events being multiquantal. Assuming that release of one quantum transfers $65 \mathrm{fC}$ of charge, then dividing the total charge carried by mEPSCs over a period of time by $65 \mathrm{fC}$ gave us a more accurate estimate of release frequency expressed as quanta/s. Averaging the first $5 \mathrm{~s}$ of $\mathrm{nAChR}$-induced burst showed that the mean frequency during this period was $330 \pm 82$ quanta/s $(n=$ 6). Application of nicotine in the presence of $\mathrm{KN}-93$ resulted in a mean frequency of $70 \pm 17$ quanta/s $(n=10 ; 21 \%$ of the frequency compared with the burst in the absence of the CaMKII inhibitor; $p<0.05$ ). This demonstrates that large-amplitude mEPSCs arise from much higher release frequencies as a result of CaMKII activation.

Our data demonstrate that blockade of CaMKII results in the attenuation of concerted release resulting in insufficient depolarization to drive the postsynaptic cell above threshold.

\section{Activation of $\mathrm{nAChRs}$ by low concentrations of nicotine is sufficient to cause concerted release}

A key question posed by this study is its biological relevance. Our results suggest that ACh concentrations between 10 and $100 \mu \mathrm{M}$ are required for mediating the nAChR effects (data not shown). Although one could argue, based on studies at the neuromuscular junction, that such concentrations are physiologically relevant, very little is known about ACh release in the CNS. Electron microscopic studies suggest that release of ACh and subsequent signaling might be mediated by "volume" transmission, dependent on diffusion of the released ACh (Contant et al., 1996; Descarries et al., 1997; Mechawar et al., 2002). If that's the case, then the actual concentrations of the transmitter at the mossy fiber synapse remains unknown. At present, there are few available tools to examine the mechanics of cholinergic transmission.

It is known that serum concentrations of nicotine reach $0.5-1$ $\mu \mathrm{M}$ during smoking (Henningfield et al., 1993). As nicotine and its metabolites are concentrated in the brain almost fivefold (Ghosheh et al., 2001), this is likely to be an underestimate of the concentrations seen at CNS synapses. We used low nicotine concentrations at RT and at physiological temperatures $\left(35^{\circ} \mathrm{C}\right)$ to examine their effects on glutamatergic mEPSCs. The results are shown in Figure 9. Nicotine at $0.5 \mu \mathrm{M}$, when applied at $35^{\circ} \mathrm{C}$ caused a $9.2 \pm 3.8$-fold increase in mEPSC frequencies $(n=3$ cells) (Fig. 9A,B). The amplitude distribution showed a distinct rightward shift even during the wash period when the frequencies had declined by $80 \%$ of the value in the presence of the agonist (Fig. 9B, right) $(p<0.0001$, control vs nicotine and control vs wash). The mean amplitudes of the mEPSCs increased from $20.4 \pm 0.7 \mathrm{pA}$ in controls to $32.4 \pm 0.6 \mathrm{pA}$ in the presence of 0.5 $\mu \mathrm{M}$ nicotine and $41.2 \pm 1.12 \mathrm{pA}$ during wash (data from three experiments, control, 1274 mEPSCs; nicotine, 7883 mEPSCs; and 2473 mEPSCs during wash; $p<0.0001$ control vs nicotine and control vs wash).

Application of $1 \mu \mathrm{M}$ nicotine at RT resulted in a robust increase in mEPSC frequencies (Fig. 9C, left). In the presence of agonist the mean frequency increased $9.5 \pm 2$-fold ( $n=5$ cells) not significantly different from that elicited by $0.5 \mu \mathrm{M}$ nicotine at physiological temperatures $(9.2 \pm 3.8$-fold; $p=0.96)$. The amplitude distribution was not significantly altered (control, 483 mEPSCs; nicotine, 2768 mEPSCs; $n=5$ cells; $p=0.4$ ) (Fig. 9C, right). The mean mEPSC amplitudes were not significantly different between controls and $1 \mu \mathrm{M}$ nicotine $(22 \pm 1.1 \mathrm{pA}$ and $23 \pm$ $0.4 \mathrm{pA}$ respectively; $n=5$ cells; $p=0.4$ ).

Measurements of calcium signals from MFBs were difficult at physiological temperatures because of increased basal noise,
A Control

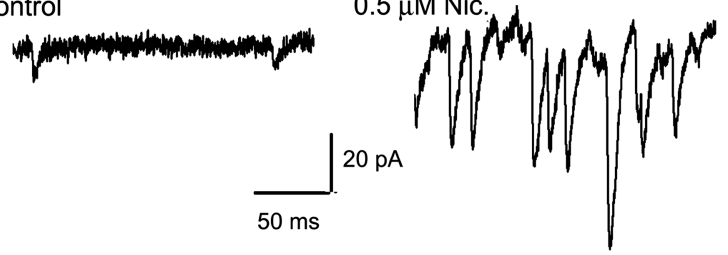

B
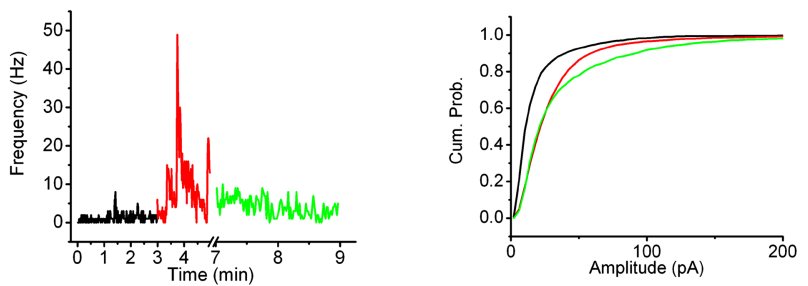

C
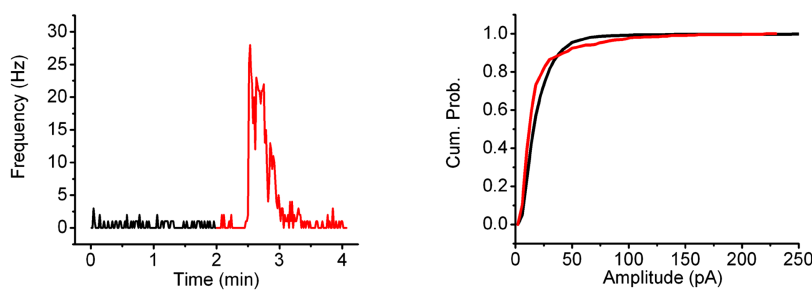

D

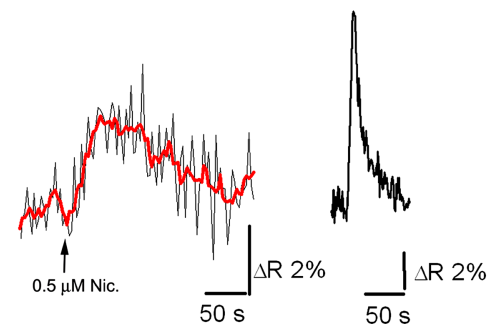

Figure 9. Responses to low nicotine concentrations. A, Left trace, Control mEPSCs. Right trace, $\mathrm{mEPSC}$ burst induced by $0.5 \mu \mathrm{m}$ nicotine at $35^{\circ} \mathrm{C}$. Nicotine $(0.5 \mu \mathrm{m})$ causes a burst of large $\mathrm{mEPSCs}$ at physiological temperatures. $\boldsymbol{B}$, Left, Frequency response to $0.5 \mu \mathrm{m}$ nicotine from a neuron (control, black; nicotine, red; and wash, green). Nicotine caused a sharp, robust increase in mEPSC frequency. Right, Cumulative probability distribution of amplitudes from three cells (color codes are the same). Low nicotine caused a long-lasting change in mEPSC amplitudes ( $p<0.0001$ compared with control, for both red and green traces). C, Left, Frequency response to application of $1 \mu \mathrm{m}$ nicotine at RT (control, black; nicotine, red). Nicotine caused a robust increase in mEPSC frequencies. Right, Cumulative probability distribution of amplitude (color code same) taken from five cells. At RT, $1 \mu \mathrm{m}$ nicotine did not alter mEPSC amplitude distribution ( $p=0.4$ compared with control). $\boldsymbol{D}$, Calcium response from a MFB to a 30 s application of $0.5 \mu \mathrm{m}$ nicotine (left trace). Nicotine causes an increase in $[\mathrm{Ca}]_{\mathrm{j}}$. The red trace is a three-point adjacent average of the raw trace. Right trace, Same bouton challenged with a 10 s application of $70 \mathrm{~mm} \mathrm{KCl}$.

spontaneous calcium transients, and possible dye sequestration. Nonetheless, examining data from 10 boutons, that did not show spontaneous activity, a distinct calcium transient was observed in response to a $30 \mathrm{~s}$ application of $0.5 \mu \mathrm{M}$ nicotine (Fig. 9D). The cumulative calcium change over a period of $200 \mathrm{~s}$ was $2.2 \pm$ 0.2 -fold that seen with a signal obtained from a $10 \mathrm{~s}$ application of HiK integrated over $60 \mathrm{~s}$; the average duration of the HiK response ( $p<0.0001,0.5 \mu \mathrm{M}$ nicotine vs HiK; paired $t$ test) suggesting a slow but significant calcium change in the boutons, as seen with $100 \mu \mathrm{M}$ ACh/At at RT.

\section{Discussion}

There is increasing evidence that information transfer across synapses can occur in the absence of presynaptic APs. An understanding of the mechanisms underlying AP-independent signal- 
ing and its biological relevance is lacking. In this study, we show that $\alpha 7$-nAChRs, via their ability to mobilize store calcium, induce concerted release of multiple quanta at the mossy fiber-CA3 pyramidal cell synapse resulting in large-amplitude mEPSCs. This process of concerted release requires the downstream activation of presynaptic CaMKII demonstrating a novel, kinasemediated, regulation of concerted release of multiple vesicles at the MFB. Furthermore, the coincidence of an overall increase in mEPSC frequencies and the CaMKII-dependent release of multiple quanta are required to drive the postsynaptic cell above threshold. This form of regulation of transmitter release taps into the RRP at this synapse, but is not subject to the negative feedback regulation by type II mGluRs characteristic of this synapse.

Our results demonstrate a regulated and a uniquely timed form of plasticity, driven by store calcium, that is responsive to a different history of synaptic activity than that mediated by presynaptic APs.

\section{Large-amplitude mEPSCs from MFBs arise from concerted release of multiple quanta}

The proportional increase of the AMPA and KA components with increasing amplitudes of individual mEPSCs is consistent with concerted release of multiple vesicles. For a postsynaptic mechanism to work, one would have to postulate equal scaling (by insertion or modification) of both postsynaptic components, possible but unlikely to occur.

In our experiments, reducing the temperature abolished the amplitude change implying a loss of efficiency in the nAChRmediated release at MFBs. These data rule out monoquantal release from large, clear vesicles based on an earlier report (Henze et al., 2002). In the small pool of large mEPSCs, a number of events had inflections in their rising phase consistent with summation. However, we believe that the only case in which inflections can be convincingly used to show concerted release would be when individual events show kinks that occur at regular intervals which are multiples of an unitary event (Williams et al., 1998), a phenomenon unlikely to occur at a complex terminal with multiple active zones.

Coupled with the large overall increases in mEPSC frequencies, one explanation for our LT data are that an additional temperature-dependent step downstream of calcium is required for concerted release.

\section{Evidence for functional $\alpha 7-\mathrm{nAChRs}$ on MFBs}

Activation of $\alpha 7$-nAChRs results in a slow calcium transient that has a rise time in the order of many seconds and returns to baseline over a period of minutes. The modulation of the calcium signal by the positive allosteric modulator of $\alpha 7-n A C h R, P N U-$ 120596 (Hurst et al., 2005), and the almost complete inhibition of the response with $125 \mathrm{nM} \alpha \mathrm{BTX}$, confirm that the calcium response in MFBs is attributable to the activation of this class of nAChRs, consistent with our electrophysiological data.

Although their conclusions about a previous report demonstrating $\alpha 7$-nAChR-mediated calcium transients from MFBs (Gray et al., 1996) might be correct, the slowness of the calcium transients explains the failure of Vogt and Regehr (2001) to detect calcium responses with rapid (1 s) agonist applications and a short imaging window. At the same time, their ability to see rapid $\alpha 7$-nAChR responses from the interneuron soma, shown also to have fast desensitizing current responses (Fayuk and Yakel, 2007), raises the possibility that there is a slow component to the presynaptic $\alpha 7-\mathrm{nAChR}$, different from that described on postsynaptic neurons. Whether this implies the existence of a heteromeric receptor, a splice variant (Cuevas and Berg, 1998), or modification of receptor kinetics by association with other proteins, remains to be seen.

\section{Involvement of store calcium}

The significant block of the calcium signal by the inhibition of RyRs confirms the dependence of the calcium transient on ER store release, predicted by our electrophysiological data (Sharma and Vijayaraghavan, 2003).

The role of ER calcium in modulating short-term plasticity at these synapses is controversial showing both potentiation (Lauri et al., 2003) or no effect (Carter et al., 2002; Breustedt and Schmitz, 2004). Although we have not addressed this issue directly, our results demonstrating a slow calcium transient in response to store calcium release would explain a lack of effect of store calcium manipulations on frequency facilitation (Breustedt and Schmitz, 2004).

Our finding that DCG-IV is much less efficacious at blocking the mEPSC burst than EPSCs at this synapse implies that nAChR effects might not be subject to the same feedback mGluRmediated regulation, seen with AP-dependent transmission.

\section{Concerted release is regulated downstream of ER calcium}

A surprising finding was that the amplitude change induced by $\mathrm{nAChR}$ activation persisted during subsequent applications of $100 \mathrm{~mm}$ sucrose. Because sucrose causes release independent of calcium changes, it is unlikely that synchrony arises from coordinated RyR-mediated calcium sparks at, or across, active zones. The most likely possibility is that calcium release from ER acts on downstream effectors to alter release. Such modulation of sucrose responses occurs at other synapses where protein kinase $\mathrm{C}$ has been shown to increase the frequency of release $\mathrm{Wu}$ and $\mathrm{Wu}$, 2001) and to increase both RRP size and vesicle refilling rates (Stevens and Sullivan, 1998).

Our data suggests some overlap between the AP-independent pool and the RRP. The large size of the MFB vesicle pool and complexity of the terminal (Rollenhagen et al., 2007) might allow for spatially selective mobilization of different subpools within the same RRP. Knowledge of the location of RyRs in the terminal will be critical in resolving this issue.

\section{Involvement of CaMKII}

The ability of CaMKII to alter release probabilities at this synapse has been shown in one instance (Salin et al., 1996). The role of CaMKII in mediating the effects of nAChRs has been documented in other systems (Damaj, 2000; Chang and Berg, 2001; Diaz-Hernandez et al., 2006; Damaj, 2007), and studies probing the mechanistic details of this signaling, clearly implicate store calcium as a trigger for nAChR-mediated CaMKII activation (Chang and Berg, 2001; Hu et al., 2002). These studies, combined with ours, suggest that activation of CaMKII might be a common mechanism in $\mathrm{nAChR}$ signal transduction.

CaMKII modulation of mEPSC frequencies is seen in hippocampal cultures (Ninan and Arancio, 2004), where the effects of the enzyme might be isoform specific (Thiagarajan et al., 2002). Our data indicate that the site of CaMKII action lies downstream of calcium, but the actual substrates of the enzyme responsible remain unknown.

Mechanisms by which CaMKII-mediated concerted release occurs remains to be investigated. It is possible that multiple vesicles are tethered to each other, as seen in ribbon synapses (Parsons and Sterling, 2003; Sterling and Matthews, 2005), or that the enzyme directly fuses multiple vesicles resulting in a form 
of compound exocytosis shown in other systems (Angleson et al., 1999). Another possibility is that CaMKII relieves lateral inhibition that then allows multiple release events to occur. There is evidence for (Dobrunz et al., 1997) and against (Abenavoli et al., 2002) lateral inhibition at other hippocampal synapses. At this juncture, all these remain speculative possibilities that need to be addressed.

A key finding from our previous work was that the burst of mEPSCs is sufficient to drive the postsynaptic neuron above its firing threshold. Postsynaptic firing coincided with the onset of the burst when frequency and amplitude changes were maximal. At low frequencies, the high-amplitude mEPSCs were not, by themselves, sufficient to drive the postsynaptic neuron above threshold (Sharma and Vijayaraghavan, 2003). Our data here shows that frequency change, in the absence of concerted release is also not sufficient for AP generation. This demonstrates that the coincidence of the two, generated by increase in $[\mathrm{Ca}]_{\mathrm{i}}$ as well as the downstream CaMKII activation, is required for postsynaptic firing independent of presynaptic APs.

\section{Potential biological relevance of AP-independent signaling}

The relevance of $\mathrm{nAChR}$-mediated postsynaptic firing remains to be elucidated. One might question, given the brevity of the burst, its relevance to synaptic strength. However, a single burst of 30-90 APs is sufficient to activate, by phosphorylation, the cAMP response element-binding protein (CREB) signaling cascade in dorsal root ganglion neurons (Fields et al., 1997). Furthermore, such bursts spaced $5 \mathrm{~min}$ apart, result in sustained activation of CREB, sufficient to alter gene expression and synaptic strength effectively (Fields et al., 1997). These results suggest a potential role for the $\mathrm{nAChR}$-dependent firing in altering synaptic strength at the CA3-mossy fiber synapse.

The role of endogenous cholinergic inputs in mediating these effects remains unknown. This is mainly because of a lack of adequate tools to examine the mechanistic underpinnings of cholinergic signaling. Our finding that low nicotine concentrations, spanning the range experienced by smokers, can induce a burst of mEPSCs with changes in amplitude speaks to the biological relevance of AP-independent signaling. It is now being realized that addiction is a problem of hedonic dyshomeostasis, where drug use is seen as an attempt at self-medication to restore the balance of affective states in the body (Koob, 1996; Koob and Le Moal, 1997). Seen from this perspective, drug addiction is a complex phenomenon involving a lot more than just activation of reward pathways. The ability of drugs like nicotine to alter synaptic plasticity is clearly in line with this reasoning. This leads to the speculation that concerted release of transmitters, induced by nicotine, might play a role in achieving an alternate homeostatic state in the brain contributing to nicotine addiction.

\section{References}

Abenavoli A, Forti L, Bossi M, Bergamaschi A, Villa A, Malgaroli A (2002) Multimodal quantal release at individual hippocampal synapses: evidence for no lateral inhibition. J Neurosci 22:6336-6346.

Alle H, Geiger JR (2006) Combined analog and action potential coding in hippocampal mossy fibers. Science 311:1290-1293.

Angleson JK, Cochilla AJ, Kilic G, Nussinovitch I, Betz WJ (1999) Regulation of dense core release from neuroendocrine cells revealed by imaging single exocytic events. Nat Neurosci 2:440-446.

Arias-Montano JA, Floran B, Floran L, Aceves J, Young JM (2007) Dopamine $\mathrm{D}(1)$ receptor facilitation of depolarization-induced release of gamma-amino-butyric acid in rat striatum is mediated by the cAMP/PKA pathway and involves P/Q-type calcium channels. Synapse 61:310-319.

Asaumi Y, Hasuo H, Akasu T (2006) Dopamine presynaptically depresses fast inhibitory synaptic transmission via D4 receptor-protein kinase A pathway in the rat dorsolateral septal nucleus. J Neurophysiol 96:591-601.

Auger C, Kondo S, Marty A (1998) Multivesicular release at single functional synaptic sites in cerebellar stellate and basket cells. J Neurosci 18:4532-4547.

Breustedt J, Schmitz D (2004) Assessing the role of GLUK5 and GLUK6 at hippocampal mossy fiber synapses. J Neurosci 24:10093-10098.

Carter AG, Vogt KE, Foster KA, Regehr WG (2002) Assessing the role of calcium-induced calcium release in short-term presynaptic plasticity at excitatory central synapses. J Neurosci 22:21-28.

Chang KT, Berg DK (2001) Voltage-gated channels block nicotinic regulation of CREB phosphorylation and gene expression in neurons. Neuron 32:855-865.

Christie JM, Jahr CE (2006) Multivesicular release at Schaffer collateralCA1 hippocampal synapses. J Neurosci 26:210-216.

Collin T, Marty A, Llano I (2005) Presynaptic calcium stores and synaptic transmission. Curr Opin Neurobiol 15:275-281.

Contant C, Umbriaco D, Garcia S, Watkins KC, Descarries L (1996) Ultrastructural characterization of the acetylcholine innervation in adult rat neostriatum. Neuroscience 71:937-947.

Cossart R, Epsztein J, Tyzio R, Becq H, Hirsch J, Ben Ari Y, Crepel V (2002) Quantal release of glutamate generates pure kainate and mixed AMPA/ kainate EPSCs in hippocampal neurons. Neuron 35:147-159.

Cuevas J, Berg DK (1998) Mammalian nicotinic receptors with alpha7 subunits that slowly desensitize and rapidly recover from alphabungarotoxin blockade. J Neurosci 18:10335-10344.

Damaj MI (2000) The involvement of spinal $\mathrm{Ca}^{2+} /$ calmodulin-protein kinase II in nicotine-induced antinociception in mice. Eur J Pharmacol 404:103-110.

Damaj MI (2007) Nicotinic regulation of calcium/calmodulin-dependent protein kinase II activation in the spinal cord. J Pharmacol Exp Ther 320:244-249.

Descarries L, Gisiger V, Steriade M (1997) Diffuse transmission by acetylcholine in the CNS. Prog Neurobiol 53:603-625.

Diaz-Hernandez M, Sanchez-Nogueiro J, Miras-Portugal MT (2006) Role of CaCMKII in the cross talk between ionotropic nucleotide and nicotinic receptors in individual cholinergic terminals. J Mol Neurosci 30:177-180.

Dobrunz LE, Huang EP, Stevens CF (1997) Very short-term plasticity in hippocampal synapses. Proc Natl Acad Sci USA 94:14843-14847.

Fayuk D, Yakel JL (2007) Dendritic $\mathrm{Ca}^{2+}$ signalling due to activation of alpha 7-containing nicotinic acetylcholine receptors in rat hippocampal neurons. J Physiol (Lond) 582:597-611.

Fields RD, Eshete F, Stevens B, Itoh K (1997) Action potential-dependent regulation of gene expression: temporal specificity in $\mathrm{Ca}^{2+}$, cAMPresponsive element binding proteins, and mitogen-activated protein kinase signaling. J Neurosci 17:7252-7266.

Fog JU, Khoshbouei H, Holy M, Owens WA, Vaegter CB, Sen N, Nikandrova Y, Bowton E, McMahon DG, Colbran RJ, Daws LC, Sitte HH, Javitch JA, Galli A, Gether U (2006) Calmodulin kinase II interacts with the dopamine transporter $\mathrm{C}$ terminus to regulate amphetamine-induced reverse transport. Neuron 51:417-429.

Foster KA, Crowley JJ, Regehr WG (2005) The influence of multivesicular release and postsynaptic receptor saturation on transmission at granule cell to Purkinje cell synapses. J Neurosci 25:11655-11665.

Galimberti I, Gogolla N, Alberi S, Santos AF, Muller D, Caroni P (2006) Long-term rearrangements of hippocampal mossy fiber terminal connectivity in the adult regulated by experience. Neuron 50:749-763.

Ghosheh OA, Dwoskin LP, Miller DK, Crooks PA (2001) Accumulation of nicotine and its metabolites in rat brain after intermittent or continuous peripheral administration of $\left[2^{\prime}-(14) \mathrm{C}\right]$ nicotine. Drug Metab Dispos 29:645-651.

Gordon GR, Bains JS (2005) Noradrenaline triggers multivesicular release at glutamatergic synapses in the hypothalamus. J Neurosci 25:11385-11395.

Goussakov IV, Fink K, Elger CE, Beck H (2000) Metaplasticity of mossy fiber synaptic transmission involves altered release probability. J Neurosci 20:3434-3441.

Gray R, Rajan AS, Radcliffe KA, Yakehiro M, Dani JA (1996) Hippocampal synaptic transmission enhanced by low concentrations of nicotine. Nature 383:713-716.

Henningfield JE, Stapleton JM, Benowitz NL, Grayson RF, London ED 
(1993) Higher levels of nicotine in arterial than in venous blood after cigarette smoking. Drug Alcohol Depend 33:23-29.

Henze DA, McMahon DB, Harris KM, Barrionuevo G (2002) Giant miniature EPSCs at the hippocampal mossy fiber to CA3 pyramidal cell synapse are monoquantal. J Neurophysiol 87:15-29.

Hu M, Liu Q, Chang KT, Berg DK (2002) Nicotinic regulation of CREB activation in hippocampal neurons by glutamatergic and nonglutamatergic pathways. Mol Cell Neurosci 21:616-625.

Hurst RS, Hajos M, Raggenbass M, Wall TM, Higdon NR, Lawson JA, Rutherford-Root KL, Berkenpas MB, Hoffmann WE, Piotrowski DW, Groppi VE, Allaman G, Ogier R, Bertrand S, Bertrand D, Arneric SP (2005) A novel positive allosteric modulator of the alpha7 neuronal nicotinic acetylcholine receptor: in vitro and in vivo characterization. J Neurosci 25:4396-4405.

Ishida A, Kameshita I, Okuno S, Kitani T, Fujisawa H (1995) A novel highly specific and potent inhibitor of calmodulin-dependent protein kinase II. Biochem Biophys Res Commun 212:806-812.

Jonas P, Major G, Sakmann B (1993) Quantal components of unitary EPSCs at the mossy fibre synapse on CA3 pyramidal cells of rat hippocampus. J Physiol (Lond) 472:615-663.

Kamiya H, Ozawa S (1999) Dual mechanism for presynaptic modulation by axonal metabotropic glutamate receptor at the mouse mossy fibre-CA3 synapse. J Physiol (Lond) 518: 497-506.

Koob GF (1996) Drug addiction: the yin and yang of hedonic homeostasis. Neuron 16:893-896.

Koob GF, Le Moal M (1997) Drug abuse: hedonic homeostatic dysregulation. Science 278:52-58.

Lauri SE, Bortolotto ZA, Nistico R, Bleakman D, Ornstein PL, Lodge D, Isaac JT, Collingridge GL (2003) A role for $\mathrm{Ca}^{2+}$ stores in kainate receptordependent synaptic facilitation and LTP at mossy fiber synapses in the hippocampus. Neuron 39:327-341.

Li G, Hidaka H, Wollheim CB (1992) Inhibition of voltage-gated $\mathrm{Ca}^{2+}$ channels and insulin secretion in HIT cells by the $\mathrm{Ca}^{2+} /$ calmodulindependent protein kinase II inhibitor KN-62: comparison with antagonists of calmodulin and L-type $\mathrm{Ca}^{2+}$ channels. Mol Pharmacol 42:489-498.

Llano I, Gonzalez J, Caputo C, Lai FA, Blayney LM, Tan YP, Marty A (2000) Presynaptic calcium stores underlie large-amplitude miniature IPSCs and spontaneous calcium transients. Nat Neurosci 3:1256-1265.

Mechawar N, Watkins KC, Descarries L (2002) Ultrastructural features of the acetylcholine innervation in the developing parietal cortex of rat. J Comp Neurol 443:250-258.

Mellor J, Nicoll RA, Schmitz D (2002) Mediation of hippocampal mossy fiber long-term potentiation by presynaptic Ih channels. Science 295:143-147.

Murphy TH, Blatter LA, Bhat RV, Fiore RS, Wier WG, Baraban JM (1994) Differential regulation of calcium/calmodulin-dependent protein kinase II and p42 MAP kinase activity by synaptic transmission. J Neurosci 14:1320-1331.

Nakayama H, Numakawa T, Ikeuchi T, Hatanaka H (2001) Nicotineinduced phosphorylation of extracellular signal-regulated protein kinase and CREB in PC12h cells. J Neurochem 79:489-498.

Ninan I, Arancio O (2004) Presynaptic CaMKII is necessary for synaptic plasticity in cultured hippocampal neurons. Neuron 42:129-141.

Oertner TG, Sabatini BL, Nimchinsky EA, Svoboda K (2002) Facilitation at single synapses probed with optical quantal analysis. Nat Neurosci 5:657-664.

Parsons TD, Sterling P (2003) Synaptic ribbon. Conveyor belt or safety belt? Neuron 37:379-382.

Regehr WG, Atluri PP (1995) Calcium transients in cerebellar granule cell presynaptic terminals. Biophys J 68:2156-2170.

Rollenhagen A, Satzler K, Rodriguez EP, Jonas P, Frotscher M, Lubke JH
(2007) Structural determinants of transmission at large hippocampal mossy fiber synapses. J Neurosci 27:10434-10444.

Saitoe M, Schwarz TL, Umbach JA, Gundersen CB, Kidokoro Y (2001) Absence of junctional glutamate receptor clusters in Drosophila mutants lacking spontaneous transmitter release. Science 293:514-517.

Salin PA, Scanziani M, Malenka RC, Nicoll RA (1996) Distinct short-term plasticity at two excitatory synapses in the hippocampus. Proc Natl Acad Sci USA 93:13304-13309.

Sharma G, Vijayaraghavan S (2001) Nicotinic cholinergic signaling in hippocampal astrocytes involves calcium-induced calcium release from intracellular stores. Proc Natl Acad Sci USA 98:4148-4153.

Sharma G, Vijayaraghavan S (2003) Modulation of presynaptic store calcium induces release of glutamate and postsynaptic firing. Neuron 38:929-939.

Shigetomi E, Kato F (2004) Action potential-independent release of glutamate by $\mathrm{Ca}^{2+}$ entry through presynaptic $\mathrm{P} 2 \mathrm{X}$ receptors elicits postsynaptic firing in the brainstem autonomic network. J Neurosci 24:3125-3135.

Silver RA, Lubke J, Sakmann B, Feldmeyer D (2003) High-probability uniquantal transmission at excitatory synapses in barrel cortex. Science 302:1981-1984.

Sterling P, Matthews G (2005) Structure and function of ribbon synapses. Trends Neurosci 28:20-29.

Stevens CF, Sullivan JM (1998) Regulation of the readily releasable vesicle pool by protein kinase C. Neuron 21:885-893.

Sutton MA, Wall NR, Aakalu GN, Schuman EM (2004) Regulation of dendritic protein synthesis by miniature synaptic events. Science 304:1979-1983.

Tang K, Wu H, Mahata SK, O'Connor DT (1998) A crucial role for the mitogen-activated protein kinase pathway in nicotinic cholinergic signaling to secretory protein transcription in pheochromocytoma cells. Mol Pharmacol 54:59-69.

Thiagarajan TC, Piedras-Renteria ES, Tsien RW (2002) alpha- and betaCaMKII. Inverse regulation by neuronal activity and opposing effects on synaptic strength. Neuron 36:1103-1114.

Tong G, Jahr CE (1994) Multivesicular release from excitatory synapses of cultured hippocampal neurons. Neuron 12:51-59.

Tsutsui M, Yanagihara N, Fukunaga K, Minami K, Nakashima Y, Kuroiwa A, Miyamoto E, Izumi F (1996) $\mathrm{Ca}^{2+} /$ calmodulin-dependent protein kinase II inhibitor KN-62 inhibits adrenal medullary chromaffin cell functions independent of its action on the kinase. J Neurochem 66:2517-2522.

Vogt KE, Regehr WG (2001) Cholinergic modulation of excitatory synaptic transmission in the CA3 area of the hippocampus. J Neurosci 21:75-83.

Wadiche JI, Jahr CE (2001) Multivesicular release at climbing fiberPurkinje cell synapses. Neuron 32:301-313.

Wall MJ, Usowicz MM (1998) Development of the quantal properties of evoked and spontaneous synaptic currents at a brain synapse. Nat Neurosci 1:675-682.

Williams SR, Buhl EH, Mody I (1998) The dynamics of synchronized neurotransmitter release determined from compound spontaneous IPSCs in rat dentate granule neurones in vitro. J Physiol (Lond) 510:477-497.

Wu XS, Wu LG (2001) Protein kinase c increases the apparent affinity of the release machinery to $\mathrm{Ca}^{2+}$ by enhancing the release machinery downstream of the $\mathrm{Ca}^{2+}$ sensor. J Neurosci 21:7928-7936.

Xu C, Datta S, Wu M, Alreja M (2004) Hippocampal theta rhythm is reduced by suppression of the H-current in septohippocampal GABAergic neurons. Eur J Neurosci 19:2299-2309.

Yamashita T, Isa T (2003) $\mathrm{Ca}^{2+}$-dependent inward current induced by nicotinic receptor activation depends on $\mathrm{Ca}^{2+} /$ calmodulin-CaMKII pathway in dopamine neurons. Neurosci Res 47:225-232.

Yeckel MF, Kapur A, Johnston D (1999) Multiple forms of LTP in hippocampal CA3 neurons use a common postsynaptic mechanism. Nat Neurosci 2:625-633. 